\title{
Methodological and physical biases in global to subcontinental borehole temperature reconstructions: an assessment from a pseudo-proxy perspective
}

\author{
Camilo Melo-Aguilar ${ }^{1,2}$, J. Fidel González-Rouco ${ }^{1,2}$, Elena García-Bustamante ${ }^{3}$, Norman Steinert ${ }^{1,2}$, \\ Johann H. Jungclaus ${ }^{4}$, Jorge Navarro ${ }^{3}$, and Pedro J. Roldán-Gómez ${ }^{1}$ \\ ${ }^{1}$ Facultad de Ciencias Físicas, Dpto. Física de la Tierra y Astrofísica, Universidad Complutense de Madrid, \\ 28040 Madrid, Spain \\ ${ }^{2}$ Instituto de Geociencias, Consejo Superior de Investigaciones Cientificas, \\ Universidad Complutense de Madrid, 28040 Madrid, Spain \\ ${ }^{3}$ Centro de Investigaciones Energéticas, Medioambientales y Tecnológicas (CIEMAT), 28040 Madrid, Spain \\ ${ }^{4}$ Max Planck Institute for Meteorology, Hamburg, Germany
}

Correspondence: Camilo Melo-Aguilar (camelo@ucm.es)

Received: 17 September 2019 - Discussion started: 10 October 2019

Revised: 24 January 2020 - Accepted: 31 January 2020 - Published: 6 March 2020

\begin{abstract}
Borehole-based reconstruction is a wellestablished technique to recover information of the past climate variability based on two main hypotheses: (1) past ground surface temperature (GST) histories can be recovered from borehole temperature profiles (BTPs); (2) the past GST evolution is coupled to surface air temperature (SAT) changes, and thus, past SAT changes can be recovered from BTPs. Compared to some of the last millennium (LM) proxy-based reconstructions, previous studies based on the borehole technique indicate a larger temperature increase during the last few centuries. The nature of these differences has fostered the assessment of this reconstruction technique in search of potential causes of bias. Here, we expand previous works to explore potential methodological and physical biases using pseudo-proxy experiments with the Community Earth System Model Last Millennium Ensemble (CESM-LME). A heat-conduction forward model driven by simulated surface temperature is used to generate synthetic BTPs that are then inverted using singular value decomposition. This procedure is applied to the set of simulations that incorporates all of the LM external forcing factors as well as those that consider the concentration of the green house gases (GHGs) and the land use land cover (LULC) changes forcings separately. The results indicate that methodological issues may impact the representation of the simulated GST
\end{abstract}

at different spatial scales, with the temporal logging of the BTPs as the main sampling issue that may lead to an underestimation of the simulated GST 20th-century trends. Our analysis also shows that in the surrogate reality of the CESM-LME the GST does not fully capture the SAT warming during the industrial period, and thus, there may be a further underestimation of the past SAT changes due to physical processes. Globally, this effect is mainly influenced by the GHG forcing, whereas regionally, LULC changes and other forcings factors also contribute. These findings suggest that despite the larger temperature increase suggested by the borehole estimations during the last few centuries of the LM relative to some other proxy reconstructions, both the methodological and physical biases would result in a underestimation of the 20th-century warming.

\section{Introduction}

Over pre-instrumental times, the climate evolution is estimated from a variety of indirect sources used as proxy indicators of climate variations (Houghton et al., 2001). During the last few decades, there have been advances in expanding and improving proxy temperature reconstructions targeting the common era (CE; Masson-Delmotte et al., 2013). This information offers a frame for addressing the 20th- 
century warming in a broader temporal context, contributing to a more suitable analysis of the forced climate system response with respect to the natural background. Overall, different hemispheric- to global-scale proxy reconstructions depict similar climate variability during the last 2000 years. However, the amplitude and timing of past climate states are still not fully constrained. For instance, the magnitude of the temperature variation from the Little Ice Age (LIA; 1450 $1750 \mathrm{CE})$ to present day displays a range of uncertainty in the estimations of different proxy sources. While some of them estimate a temperature increase of $\sim 0.6^{\circ} \mathrm{C}$ (e.g., Ammann and Wahl, 2007), other sources suggest a larger warming of $\sim 1$ to $\sim 1.4^{\circ} \mathrm{C}$ (e.g., Pollack and Smerdon, 2004; Frank et al., 2007). In general, there are uncertainties regarding the amplitude of low-frequency changes within the last millennium (LM) as in the transition from the Medieval Climate Anomaly (MCA; 950-1250 CE). The magnitude of such changes depends on the climate sensitivity of the system, and it is important that reconstructions and climate models are consistent in its estimation (Fernández-Donado et al., 2013). Therefore, assessing the origin and levels of these uncertainties in the amplitude and time of the temperature changes is pivotal in the context of LM climate variations.

One proxy reconstruction that yields a larger warming from the LIA to present is that which arises from the borehole technique (Jansen et al., 2007; Fernández-Donado et al., 2013). This method is based on the assumption that the soil captures the surface climatic signal due to the conductive heat transport of the ground surface temperature (GST) variations into the subsurface. Therefore, the inversion of borehole temperature profiles (BTPs) provides an estimation of the past GST variations (Pollack and Huang, 2000). In addition, it is also assumed that the surface air temperature (SAT) is strongly coupled to GST (Smerdon et al., 2004), and thus, borehole reconstructions stand as a good proxy of the past SAT variation. Due to the conductive propagation of the temperature signal with depth, only the low-frequency variations are recorded in the subsurface (Pollack and Huang, 2000), and consequently, the inversion of BTPs can offer an estimation of centennial long-term trends.

The borehole-reconstructed temperatures at hemispheric scales have been subject to assessment and debate during the last few decades due to their estimated multicentennial trend of ca. $1{ }^{\circ} \mathrm{C}$ over the 1500-2000 CE period, a relatively large value in comparison with other proxy sources (Jones et al., 2009; Fernández-Donado et al., 2013; MassonDelmotte et al., 2013). It has been discussed whether some methodological limitations and environmental or physical factors may somewhat hinder the achievement of robust borehole-based estimations of past temperature trends (e.g., Rutherford and Mann, 2004; Pollack and Smerdon, 2004; González-Rouco et al., 2009). Methodological aspects refer to a variety of issues that encompass the following: first, sitespecific processes contributing to noise in BTPs, like interactions with orography and hydrology, leading to horizontal (vertical) advection (convection) that renders the conductive regime assumption invalid and second, sampling irregularities such as low-density and/or irregular spatial distribution of boreholes at regional and larger spatial scales, regional differences and variability in logging dates and depth of profiles, vertical resolution, errors in measurements, etc(Pollack and Huang, 2000; Bodri and Cermak, 2007). All of these methodological issues may have an impact on the recovery of past GSTs from BTPs. In turn, changes in surface environment or boundary conditions may have an impact on the recovery of past SAT variations from reconstructed GSTs, i.e., on SAT-GST coupling. Long-term variability in surface climate parameters like changes in snow cover, freezing, land use and land cover (LULC), or evaporation changes may therefore play a role in the surface energy balance and thus in SAT-GST interactions (Mann and Schmidt, 2003; Smerdon et al., 2004; González-Rouco et al., 2003, 2009).

The impacts of methodological issues on hemisphericscale reconstructions, like the uneven geographical distribution of the borehole sites and the spatial gridding of the data, were discussed by Rutherford and Mann (2004) and Pollack and Smerdon (2004) using the observational borehole dataset (Huang and Pollack, 1998). They showed that the spatial aggregation and weighting scheme, used in Huang et al. (2000) and Harris and Chapman (2001), has minor implications for the warming trends indicated by these reconstructions. They also argued that the predominantly midlatitude distribution of boreholes should be able to capture the Northern Hemisphere (NH) temperature evolution. Likewise, Beltrami and Bourlon (2004) addressed the spatial aggregation of the borehole sites to obtain $\mathrm{NH}$ averages, using gridding instead of geographic aggregation and various grid cell sizes. They reported a $1{ }^{\circ} \mathrm{C}$ NH GST increase for the 1500-1980 CE period, consistent with the Huang et al. (2000) and Harris and Chapman (2001) estimations. Additional sampling issues like differences in timing and depth of borehole logs have received less attention. Most of the $\operatorname{logs}$ were done before $1980 \mathrm{CE}$. Thus, the aggregation of this information should be done with caution as the post 1980 years, when warming has been larger, are underrepresented. Their influence is thus difficult to assess in studies with real BTPs. Huang et al. (2000) used fixed century-long ramp trends for each BTP to estimate hemispheric long-term temperature variations from 1500 to $2000 \mathrm{CE}$. The estimated trend does not fully capture the warming within the last few decades of the 20th century, as the bulk of the borehole sites were logged before 1990 CE. Harris and Chapman (2001) reconstructed the 1500-2000 CE NH midlatitude temperatures from a set of BTPs that were taken from a common time frame. They forward propagated each reduced temperature profile by considering a constant temperature evolution from the logging date up to $1995 \mathrm{CE}$. Both of these analyses represent a partially muted estimation of the industrial warming since only a small portion of BTP data include information of the last few decades of the 20th century (Pollack and Smer- 
don, 2004; Jones et al., 2009). Both works yield a similar NH GST increase and thus an equivalent SAT increase, considering SAT-GST coupling, of about $\sim 1{ }^{\circ} \mathrm{C}$ for the 1500 2000 CE interval.

The sensitivity of the SAT-GST coupling to some physical processes at the surface has also been addressed. The discussion has been focused on whether variations in the longterm behavior of surface properties may result in a biased representation of the SAT histories by the reconstructed GST (Jansen et al., 2007). This thread of analysis has benefited considerably from introducing contributions from modeling. For instance, the influence of snow cover was analyzed by various studies under the hypothesis that changes in snow cover may influence the SAT-GST offset and produce longterm drifts in air-ground coupling. Bartlett et al. (2005) studied this issue in multidecadal observational records, and several studies (Mann and Schmidt, 2003; Chapman et al., 2004; Schmidt and Mann, 2004) used 50-year long simulations with the Goddard Institute for Space Studies (GISS) ModelE general circulation model (GCM). Their results suggest that hemispheric-scale reconstructions are unlikely to suffer from snow cover biases. Nevertheless, long-term changes in snow cover may alter SAT-GST tracking by introducing transient and persistent long-term signatures in the coupling, for example by virtue of changes in external forcings. GonzálezRouco et al. (2003, 2009) evaluated this at a multicentennial timescale by considering millennia-long simulations of the coupled atmosphere-ocean GCM ECHO-G (Legutke and Voss, 1999), driven by both natural (solar and volcanic) and anthropogenic (greenhouse gases; GHGs) forcing factors. They found that in spite of existing decadal variability, SAT-GST coupling was reasonably stable at global and hemispheric scales, thus supporting the use of BTPs at those scales. At regional scales, snow cover trends may develop that compromise BTP-based reconstructions.

Other issues that may play a role in disrupting SAT-GST coupling through changes in the energy balance and that have received some attention are soil moisture variations (González-Rouco et al., 2009; Cermak and Bodri, 2018) and LULC changes (Cermak et al., 2017; MacDougall and Beltrami, 2017). Melo-Aguilar et al. (2018) addressed these issues by considering for the first time SAT-GST coupling in a large ensemble of simulations of the LM (CESM-LME; Otto-Bliesner et al., 2016), which includes a sub-ensemble of experiments involving a realistic setup of all-forcing natural (solar, volcanic and orbital) and anthropogenic (GHG, anthropogenic aerosols and LULC changes) forcing factors as well as setups of specific single-forcing sub-ensembles. This allowed the separation of the effect of each forcing and understanding the integral effects when all forcings were used from the single forcing contributions and feedbacks. At global and hemispheric scales, SAT-GST coupling still holds in the all-forcings simulations as a result of compensating effects of various forcings contributing to the energy balance. At regional scales, SAT-GST coupling is compro- mised by the influence of specific forcings and often amplified by changes in snow cover. This is relevant for global and continental BTP-based reconstructions because spatial sampling of BTPs should be representative of the target signal and avoid locations where SAT-GST becomes progressively decoupled.

An evaluation of the impacts of methodological and physical issues on borehole-based reconstructions can be done by considering model simulations as a surrogate reality for the actual climate evolution (Smerdon, 2012). The simulations are considered as physically plausible climate realizations, compatible with the external forcings imposed and complex enough to allow for a credible implementation of the reconstruction method. The use of millennium-length GCM simulations has provided a long-term framework in which to analyze the physical background of the SAT-GST relationship and has allowed for the development of such pseudoproxy experiments (PPEs). For instance, González-Rouco et al. (2006) used LM simulations (1000-1990 CE) from the ECHO-G model in a PPE. They used simulated GSTs and a forward model to simulate BTPs of $600 \mathrm{~m}$ depth. These were subsequently inverted, following standard procedures in borehole reconstruction strategies, and a low-pass-filtered version of SAT long-term trends that could be compared afterwards to the simulated SATs for verification was obtained. Thus, they found that the method could appropriately retrieve past SAT long-term trends. In addition to this idealized case in which BTPs would be available for every model grid point, they also implemented the method in a more realistic case by limiting the sampling of BTPs in order to replicate their actual distribution in reality. This exercise rendered similar robust results. González-Rouco et al. (2009) extended this analysis in order to include the effects of the variability in the timing of BTP logging dates and their depths for a specific example over North America. Their results suggest that such variability does not prevent the borehole technique from retrieving the North American 20th-century warming. GarcíaGarcía et al. (2016) used the LM all-forcing simulations from state-of-the-art Earth system models (ESMs) within the frame of the CMIP5/PMIP3 (Coupled Model Intercomparison Project phase 5/Paleoclimate Modeling Intercomparison Project phase 3; Taylor et al., 2012). They followed the idealized approach in González-Rouco et al. (2006), sampling the full model grid over land. This allowed for a demonstration of the performance of the borehole method over the current generation of ESMs, involving different land models and surface parameterizations.

The previous studies indicate that, globally, GST should be a good proxy of the past long-term SAT variations. Additionally, they support the overall performance of the borehole method at hemispheric and global scales under realistic scenarios involving a full setup of PMIP3 natural and anthropogenic forcings (Schmidt et al., 2011, 2012). In this work, we elaborate from previous analyses and present a set of PPEs in which we implement a borehole reconstruc- 
tion strategy using LM simulations of an ESM and assess reconstructions performance for a range of spatial scales. We update analyses of methodological and physical influences on GST reconstructions and SAT-GST coupling, respectively, that had not been systematically addressed before. We build on the analysis of Melo-Aguilar et al. (2018) by using the same Community Earth System Model LM ensemble (CESM-LME hereafter) and design PPEs to evaluate the influence of methodological sampling issues at global and regional scales by considering the actual distribution of BTPs as well as their depths and logging times. Additionally, we use a sub-ensemble of simulations, incorporating either the full setup of natural and anthropogenic forcings, the so-called all-forcing experiments (ALL- $F$ hereafter), or sub-ensembles of experiments incorporating specific individual forcings, the so-called single-forcing experiments (single- $F$ hereafter). This allows for attainment of understanding of how forcing factors and their influences on SAT-GST coupling can impact the results in different regions. Particularly, we focus on the GHG and LULC only (GHG-only and LULC-only hereafter) ensembles due to them having the highest potential for impacting the SAT-GST relationship (Melo-Aguilar et al., 2018).

In the first part of the paper (Sect. 2), the general characteristics of the model and the simulations employed in this study are presented. Subsequently, Sect. 3 describes the pseudoproxy configuration considered herein. Results are described in Sect. 4, including the specific effects due to the methodological (Sect. 4.1) and the physical issues (Sect. 4.2). The latter also independently considers the contribution of the LULC and GHG external forcings. Finally, Sect. 5 wraps up conclusions and discussion of the main results.

\section{ESM simulations}

CESM-LME simulations covering the period 850-2005 CE produced with the Community Earth System Model version 1.1 (CESM1; Hurrell et al., 2013) are used. The CESM1 includes the Atmosphere Model version 5 (Neale et al., 2012) and the Parallel Ocean Program version 2 (Smith et al., 2010) as well as the Los Alamos sea ice model (Hunke et al., 2015). The CESM-LME has a horizontal resolution of $\sim 2^{\circ}$ over the atmosphere and land and $\sim 1^{\circ}$ over the ocean and sea ice areas.

The Community Land Model version 4 (CLM4; Lawrence et al., 2011) represents the land surface component in the CESM1. One of the main characteristics of the CLM4 is that the bottom boundary condition placement (BBCP), at $42.1 \mathrm{~m}$ depth, is the deepest among the current generation of land surface models, with a soil column discretized into 15 layers (Table 1) including up to five additional layers in the overlying snowpack. In this respect, the CLM4 includes some improvements in the representation of some surface processes, relative to previous versions and arguably to other
Table 1. Soil layers and node depths in CLM4. The node depth, which indicates the depth where the thermal properties are defined for soil layers (Oleson et al., 2010), does not necessarily coincide with the center of the layer depth.

\begin{tabular}{lrr}
\hline Layer & Layer depth (meters) & Node depth (meters) \\
\hline L1 & 0.017 & 0.007 \\
L2 & 0.045 & 0.027 \\
L3 & 0.090 & 0.062 \\
L4 & 0.165 & 0.118 \\
L5 & 0.289 & 0.212 \\
L6 & 0.492 & 0.366 \\
L7 & 0.828 & 0.619 \\
L8 & 1.382 & 1.038 \\
L9 & 2.296 & 1.727 \\
L10 & 3.801 & 2.864 \\
L11 & 6.284 & 4.739 \\
L12 & 10.377 & 7.829 \\
L13 & 17.125 & 12.925 \\
L14 & 28.252 & 21.326 \\
L15 & 42.103 & 35.177 \\
\hline
\end{tabular}

models (García-García et al., 2019). These improvements include a better description of ground evaporation, thermal and hydrology properties of organic soils, snow albedo, snow cover fraction, and burial fraction of vegetation by snow (Oleson et al., 2010). Such features make the CLM4 specifically suited for the purpose of this work as they allow for a state-of-the-art representation of the energy transfer between the atmosphere and the soil, a key aspect in the SAT-GST relationship. Further, the relatively deep BBCP allows for a better representation of the downward propagation of the temperature signal at longer (e.g., decadal and centennial) timescales (Alexeev et al., 2007; Stevens et al., 2007; MacDougall et al., 2008).

The CESM-LME includes an ensemble of ALL- $F$ simulations that incorporates the complete set of agreed CMIP5/PMIP3 LM external forcings (Schmidt et al., 2011, 2012), including the natural and anthropogenic components. To date, a total of 13 ALL- $F$ simulations are available. Additionally, smaller ensembles of single-forcing simulations, which consider each of the LM external forcings separately, are included (see Table 2 for details and references therein). This work makes use of the ALL- $F$ ensemble as well as the GHG- and the LULC-only ensembles. Table 3 presents a detailed description of the original model output as it is described in Otto-Bliesner et al. (2016).

\section{Experimental design}

The theoretical basis for the borehole temperature reconstruction states that the subsurface contains a thermal signature of the past surface temperature variations due to the superposition of the downward temperature signal propagat- 
Table 2. External forcing reconstructions used in the CESM-LME, both in the ALL- $F$ and the single- $F$ sub-ensembles. Legend for external forcing: SOL, changes in total solar irradiance; VOLC, volcanic activity; GHG, concentrations of the well-mixed greenhouse gases $\mathrm{CO}_{2}$, $\mathrm{CH}_{2}$ and $\mathrm{N}_{2} \mathrm{O}$; LULC, land use land cover (changes); ORBs, orbital variations; and OZ/AERs, anthropogenic ozone and aerosols.

\begin{tabular}{ll}
\hline Forcing & Reference \\
\hline ALL-F & - \\
\hline SOL & Vieira et al. (2011) \\
\hline VOLC & Gao et al. (2008) \\
\hline GHG & MacFarling Meure et al. (2006) \\
\hline LULC & $\begin{array}{l}\text { Pongratz et al. (2008) dataset, spliced to Hurtt et al. (2009) at 1500 CE. The only } \\
\text { plant functional types (PFTs) that are changed are those for crops and pasture; } \\
\text { all other PFTs remain at their 1850 control prescriptions }\end{array}$ \\
\hline ORBs & $\begin{array}{l}\text { The CESM model adjusts yearly orbital position (eccentricity, obliquity and } \\
\text { precession) following Berger et al. (1993) }\end{array}$ \\
\hline OZ/AERs & $\begin{array}{l}\text { Fixed at the 1850 control simulation values until 1850 CE when the evolving an- } \\
\text { thropogenic changes up to 2005 CE. Stratospheric aerosols are prescribed in the } \\
\text { model as a fixed single-size distribution in the three layers in the lower strato- } \\
\text { sphere above the tropopause. The ozone forcing is from the Whole Atmosphere } \\
\text { Community Climate Model (WACCM) }\end{array}$ \\
\hline
\end{tabular}

Table 3. CESM-LME simulations used in this study. The first and second columns present the abbreviations used in this paper for the ensembles and the ensemble members, respectively. The ID of the original experiment files is provided in the third column.

\begin{tabular}{lll}
\hline Ensemble abbreviation & Ensemble member & Simulation identification (ID) \\
\hline ALL-F & ALL- $F_{i}$ & b.e11.BLMTRC5CN.f19_g16.0i \\
& $i=1, \ldots, 13$ & $i=01, \ldots, 13$ \\
\hline GHG-only & $\mathrm{GHG}_{i}$ & b.e11.BLMTRC5CN.f19_g16.GHG.00i \\
& $i=1,2,3$ & $i=1,2,3$ \\
\hline LULC-only & LULC $_{i}$ & b.e11.BLMTRC5CN.f19_g16.LULC_HurttPogratz.00i \\
& $i=1,2,3$ & $i=1,2,3$ \\
\hline
\end{tabular}

ing onto the background geothermal gradient. Therefore, the inversion of BTPs can yield information of the past surface temperature changes. The information of the last 500 to 1000 years is retained within the upper few hundred meters of the subsurface (Beltrami and Bourlon, 2004). Thus, BTPs of at least $300 \mathrm{~m}$ depth are required to retrieve the past 500 years (Jaume-Santero et al., 2016), whereas deeper profiles of at least $500 \mathrm{~m}$ are necessary to retrieve information of the complete LM (Pollack and Huang, 2000).

Within the model world, the depths of BTPs are limited to the land model depth. Although the CLM4 has the deepest BBCP among the current land surface models, it is still too shallow to directly provide such deep BTPs to account for LM temperature variations (see Table 1). Consequently, these profiles must be synthetically generated from the surrogate reality of the simulated world as in González-Rouco et al. (2006). The following section provides an overall description of the models employed in this study to simulate the synthetic BTPs as well as for the inversion of the result- ing profiles. Further details can be found in Mareschal and Beltrami (1992).

\subsection{Forward and inverse models}

The BTPs are determined by the combination of the geothermal heat flux, a reference ground temperature and the temperature perturbation $T_{\mathrm{t}}(z)$ induced by the surface temperature variations, as follows:

$T(z)=T_{0}+q_{0} R(z)+T_{\mathrm{t}}(z)$

where $q_{0}$ represents the surface heat flow density, $R(z)$ is the thermal depth and $T_{0}$ is a reference ground temperature. In the forward model, the quasi-steady-state component, $T_{0}+q_{0} R(z) t$, can be set equal to 0 because the aim is to derive $T(z)$ as a function of only the past surface temperature variations. The forward model thus determines the transient perturbation component $T_{\mathrm{t}}(z)$, which can be thought of as 
the anomaly with respect to the quasi-steady-state thermal regime.

The propagation of the surface temperature signal within the subsurface is controlled by the one-dimensional timedependent heat conduction equation (Carslaw and Jaeger, 1959):

$$
\frac{\partial T}{\partial t}=\kappa \frac{\partial^{2} T}{\partial z^{2}}
$$

with $\kappa$ as the thermal diffusivity and $z$ and $T$ as depth and temperature, respectively. Equation (2) is solved for an instantaneous temperature change at time $t$ before present as

$T_{\mathrm{t}}(z)=\Delta T \operatorname{erfc}\left(\frac{z}{2 \sqrt{\kappa t}}\right)$,

where "erfc" is the complementary error function. $T_{\mathrm{t}}(z)$ can be modeled by considering the temperature variations at the surface as a series of $K$ time step temperature changes. In this way, each step imprints a thermal signature in the subsurface that is merged to the signature of the previous step. Thus, $T_{\mathrm{t}}(z)$ is given by (Mareschal and Beltrami, 1992)

$T_{\mathrm{t}}(z)=\sum_{k=1}^{K} \Delta T_{k}\left[\operatorname{erfc}\left(\frac{z}{2 \sqrt{\kappa t_{k}}}\right)-\operatorname{erfc}\left(\frac{z}{2 \sqrt{\kappa t_{k-1}}}\right)\right]$,

where $\Delta T_{k}$ are the surface temperature changes for $K$ time intervals, each value representing an average over time $\left(t_{k}-\right.$ $\left.t_{k-1}\right)$.

Equation (4) is used to create synthetic BTPs, using LM surface temperature annual anomalies from the CESM-LME as the upper boundary condition. Although the synthetic temperature profile represents only the transient perturbation component, $T_{\mathrm{t}}(z)$, of the BTP, it will be denoted as BTP thorough the document to avoid confusion. $T_{\mathrm{t}}(z)$ is evaluated at every $1 \mathrm{~m}$ depth interval up to a depth of $600 \mathrm{~m}$ in order to accommodate for the propagation of the LM surface temperature variations. Subsequently, the upper $20 \mathrm{~m}$ of the resulting BTPs is removed in order to avoid the influence of the annual signal and reproduce realistic depths of the water table (Jaume-Santero et al., 2016). The thermal diffusivity used in the geothermal models is $1.5 \times 10^{-6} \mathrm{~m}^{2} \mathrm{~s}^{-1}$, obtained from the values of the bedrock thermal conductivity $\left(3.0 \mathrm{~W} \mathrm{~m}^{-1} \mathrm{~K}^{-1}\right)$ and volumetric heat capacity $(2 \times$ $10^{6} \mathrm{~J} \mathrm{~m}^{-3} \mathrm{~K}^{-1}$ ) of the CLM4 (Lawrence et al., 2011).

For the inversion of the synthetic BTPs, singular value decomposition (SVD; Mareschal and Beltrami, 1992) is applied to retrieve the past long-term surface temperature variations. For the present work, the inverse model consists of a series of 15-year step changes in surface temperature histories following García-García et al. (2016). Different parameterizations were also tested (e.g., 20-year or 25-year step changes; not shown) and showed results consistent with the 15 -year discretization. The latter was finally selected because it yielded a convenient representation of the GST histories.
Likewise, the number of retained singular values is also important. The presence of small singular values leads to an unstable solution dominated by noise, while the use of only a few principal components (PCs) result in a smoothed lowresolution solution (Beltrami and Bourlon, 2004). The selection of the number of singular values is done by setting an eigenvalue cutoff, from which smaller values are eliminated. In this study we have used a cutoff value of $1.5 \times 10^{-1}$ from which the solution is the linear combination of the three leading modes. We have additionally explored the effect on the solution of retaining four and five PCs.

\subsection{Pseudo-proxy setup}

The assessment of the impacts of the methodological and physical issues described above on borehole temperature reconstructions, is done by designing two pseudo-proxy configurations. First, a so-called ideal borehole scenario (IBS) is considered, in which a BTP is simulated at every land model grid point up to a depth of $600 \mathrm{~m}$. This scenario is also characterized by a homogeneous logging date at the end of the CESM-LME simulation period (2005 CE) at every grid point. The latter is achieved by driving the forward model with the annual temperature anomalies calculated with respect to the 850-2005 CE mean. Subsequently, each of these BTPs is inverted, and a latitude weighted average is used to obtain the global mean. A similar approach has been used in previous works showing that under such an idealized configuration, the borehole technique is able to retrieve the simulated surface temperature variations at the global scale (González-Rouco et al., 2006; García-García et al., 2016). Hence, this scenario provides a benchmark experiment that will allow for an evaluation of the impacts of having some methodological constraints that mimic those in reality. The IBS scenario embraces two cases. On the one hand, the model soil temperature (ST) at layer $12\left(\mathrm{ST}_{\mathrm{L} 12} ; \sim 7.8 \mathrm{~m}\right.$ depth) is used as the upper boundary condition ( $\left.\operatorname{IBS}_{\mathrm{L} 12}\right)$. This case represents the ideal scenario in which to generate the pseudo-reconstructed GSTs. On the other hand, the $2 \mathrm{~m}$ air temperature model output is employed ( IBS $_{\mathrm{SAT}}$ ) in order to obtain an ideal case of pseudo-reconstructed SATs. We use the $\mathrm{ST}_{\mathrm{L} 12}$ as the reference ST to force the $\mathrm{IBS}_{\mathrm{L} 12}$ forward model because in the upper 10 layers, the CLM4 is hydrologically active and it is interesting to keep this realism in the synthetic BTPs. Additionally, this depth is consistent with using annual resolution in the model data as at this level the annual wave is very damped in amplitude, and layers below start to filter out decadal timescales. Nevertheless, this decision does not influence results significantly.

Second, a more realistic arrangement of the available global borehole network is implemented ( $\left.B_{\text {mask }}\right)$, including the actual spatial distribution of the borehole sites as well as their real $\log$ depths and dates. This information is obtained from the "Global Database of Borehole Temperatures and Climate Reconstructions" (Huang and Pollack, 1998). Only 


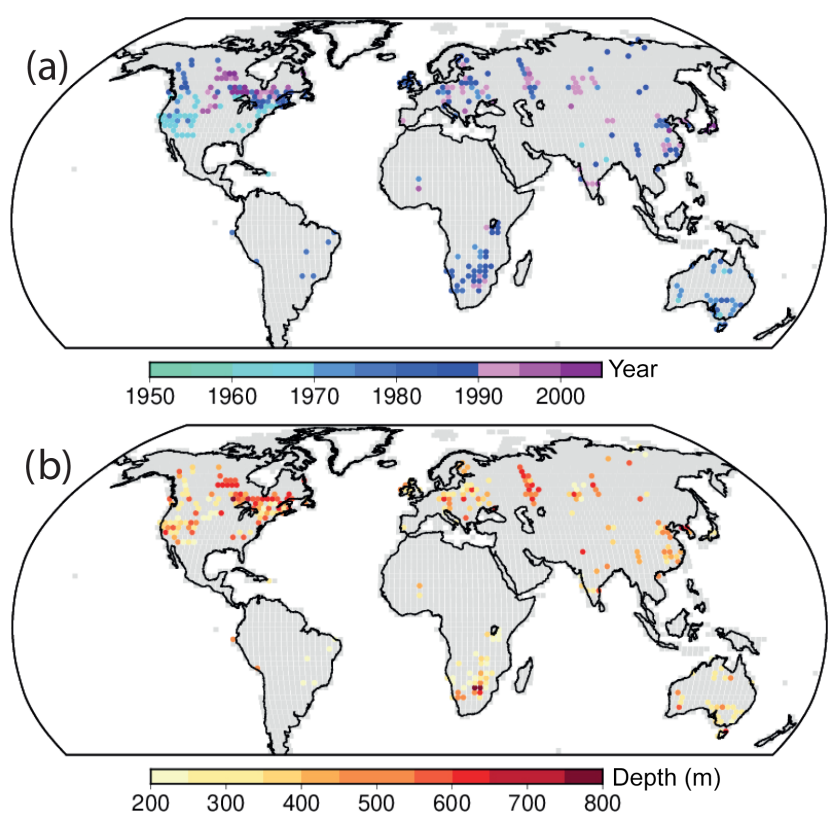

Figure 1. Spatial distribution of (a) the logging date and (b) the depths in the actual borehole network.

the BTPs deeper than $200 \mathrm{~m}$ are considered in this step since the focus is on multidecadal to centennial timescales within the LM as in previous reconstructions works (e.g., Huang et al., 2000; Beltrami and Bourlon, 2004). After this selection, a total of $970 \operatorname{logs}$ are retained. For this setup, each of the borehole sites is placed on a specific land model grid point according to their geographic information (Fig. 1). If more than one borehole corresponds to the same model grid point, only one of them is retained, prioritizing the most recent one to allow for the climatic signal of the last few decades of the 20th century to be represented. Additionally, for the bulk of the cases, the most recent borehole records coincide with the deepest ones. We finally kept 301 grid points that are the nearest colocated with any of the real borehole locations. Once the spatial distribution of the borehole network is represented in the CESM-LME grid, the $\mathrm{LM} \mathrm{ST}_{\mathrm{L} 12}$ series at each of these grid points is trimmed at the actual logging date according to the date distribution (Fig. 1a). Then, the temperature anomalies are calculated with respect to the trimmed period mean. The resulting anomaly time series are subsequently used to force the forward model at each grid point, generating a pseudo-BTP that is shortened to the actual borehole depth (Fig. 1b) in order to keep this configuration as realistic as possible. In this configuration, the inversion of the individual profiles yields information until the date when they were logged; therefore the reconstructed period is highly variable. The latter seemingly has an impact on the estimation of global averages since closer to present day the number of available sites decreases. Indeed ca. half of the borehole profiles were logged before $1980 \mathrm{CE}$, and only $\sim 20 \%$ of the sites have been measured after 1990 CE. In order to account for such variability in the logging dates, global and regional averaging is done on a yearly basis (Jaume-Santero et al., 2016).

The results from the idealized IBS and the more realistic $B_{\text {mask }}$ configuration are then compared in order to evaluate the methodological limitations as well as the potential physical bias. As the methodological aspects are related to the suitability of the spatiotemporal distribution of the borehole network to retrieve the past GST variations, $\mathrm{IBS}_{\mathrm{L} 12}$ allows for an assessment of these type of limitations when compared to $B_{\text {mask }}$; the differences between them informing about the effect of the methodological variants. This assessment is initially developed at the global scale, and then, it is extended to smaller spatial domains in order to address the implications on areas with different spatiotemporal borehole distribution. In this part of the analysis only the ALL- $F$ ensemble is used. In this work, GST, which is ultimately the target signal of $\mathrm{IBS}_{\mathrm{L} 12}$, is defined as the $\mathrm{ST}$ at the first soil layer $\left(\mathrm{ST}_{\mathrm{L} 1}\right.$; $0.007 \mathrm{~m}$ depth), following the same convention as in MeloAguilar et al. (2018).

The physical-related aspects and their influence on the estimates are subsequently explored via the comparison with IBS $_{\text {SAT }}$ because any deviation from the pseudo-reconstructed SAT would be the result of the physical SAT-GST decoupling. Moreover, while the differences between the IBS $_{\mathrm{SAT}}$ and the $\mathrm{IBS}_{\mathrm{L} 12}$ cases would provide information about the individual contribution of the physical aspects in the interpretation of the SAT variations from the pseudo-reconstructed GST and the differences between $\mathrm{IBS}_{\mathrm{L} 12}$ and $B_{\text {mask }}$ include the effect of the methodological sampling issues described above, the differences between $\mathrm{IBS}_{\mathrm{SAT}}$ and $B_{\text {mask }}$ allow for the estimation of the combined effects of both the methodological constraints and the physical processes. Besides the ALL- $F$ ensemble, in this analysis the GHG- and LULC-only ensembles are also considered in order to estimate their specific contribution to the potential physical biases. Therefore, the previous PPE setups $\left(\mathrm{IBS}_{\mathrm{SAT}}, \mathrm{IBS}_{\mathrm{L} 12}\right.$ and $B_{\text {mask }}$ ) are run for each of the simulations in the ALL- $F$ and GHG- and LULC-only ensembles.

In order to allow for an easy identification of the different abbreviations referenced along the document and their precise meaning, Table 4 contains a detailed description of them.

\section{Results}

The results of generating a variety of PPEs are reported herein: first, those related to methodological sampling issues (Sect. 4.1) and second, those addressing SAT-GST coupling (Sect. 4.2).

\subsection{Methodological issues}

The comparison of the simulated global GST anomalies within the $\mathrm{IBS}_{\mathrm{L} 12}$ and the $B_{\text {mask }}$ pseudo-reconstructions in 
Table 4. Abbreviations used in this paper.

\begin{tabular}{ll}
\hline Abbreviation & Meaning \\
\hline GST & $\begin{array}{l}\text { Simulated ground surface temperature defined as the first soil layer temperature } \text { ST }_{\mathrm{L} 1} ; \\
0.007 \mathrm{~m} \text { depth) }\end{array}$ \\
\hline SAT & Simulated $2 \mathrm{~m}$ air temperature. Original model output TREFHT \\
\hline IBS $_{\mathrm{L} 12}$ & $\begin{array}{l}\text { Ideal borehole scenario created from } \mathrm{ST}_{\mathrm{L} 12} \text { as the boundary condition for the forward } \\
\text { model }\end{array}$ \\
\hline IBS $_{\mathrm{SAT}}$ & $\begin{array}{l}\text { Ideal borehole scenario created from SAT as the boundary condition for the forward } \\
\text { model }\end{array}$ \\
\hline GST $_{\text {mask }}$ & $\begin{array}{l}\text { GST masked with the realistic representation of the variability in the spatiotemporal dis- } \\
\text { tribution of the global borehole network. In some cases GST mask refers to the full spa- } \\
\text { tial + date sampling, whereas in other cases it refers only to spatial sampling (i.e., Fig. 4) }\end{array}$ \\
\hline$B_{\text {mask }}$ & $\begin{array}{l}\text { Realistic scenario of the borehole temperature inversions including sampling in space, } \\
\text { time and depth. It may also refer to the cases in which the sampling is only in space or } \\
\text { space }+ \text { depth (i.e., Figs. } 2 \text { and } 4)\end{array}$ \\
\hline
\end{tabular}

the ALL- $F_{2}$ and ALL- $F_{5}$ members of the ALL- $F$ ensemble are represented as an example in Fig. 2a. These members were selected because they represent two possible results of the pseudo-reconstructed GST in the $B_{\text {mask }}$ configuration, which are discussed herein. Similar results are obtained if other members are selected. In general, the $\mathrm{IBS}_{\mathrm{L} 12}$ pseudo-reconstruction reasonably reproduces the gross features of the low-frequency GST variations over the LM in the CESM-LME. For instance, a small nonsignificant multicentennial cooling from the MCA to the LIA can be detected, and the warming over industrial times is successfully captured in both cases. Within the LIA and back to the MCA, the filtering effect produced by the heat diffusion averages over intervals of multidecadal and centennial warming and cooling. Changes in the past, like the simulated MCA warming, get damped in BTPs because of this effect, and a very smooth version of them is recovered by the reconstruction. Nevertheless, in model experiments that simulate larger MCA-LIA changes, the borehole reconstruction is able to recover somewhat warmer temperatures during the MCA if the depth of the anomalies and the number of eigenvalues retained are adequate (González-Rouco et al., 2006, 2009).

Therefore, $\mathrm{IBS}_{\mathrm{L} 12}$ qualitatively reproduces the long-term trends in both examples of Fig. 2a. However, the masked inversion $\left(B_{\text {mask }}\right)$ reproduces identical results in the case of ALL- $F_{5}$ but diverges from ALL- $F_{2}$ in the last few decades of the 20th century. This would suggest that the results of $B_{\text {mask }}$ can be simulation dependent, i.e., dependent on the different initial conditions and therefore on internal variability. In order to evaluate this, a more quantitative estimation of trends is needed, one that allows for a comparison of the idealized and masked pseudo-reconstructions and also a comparison of both of them with the simulated time series. To facilitate this, two approaches are proposed. One of them is to make a simple linear fit of the temperatures, either simulated or pseudo-reconstructed over a reference period considered. As this approach can potentially be affected by the different discretization of the simulated (annual resolution) and pseudo-reconstructed (15-year time steps) GSTs, a second strategy is applied in which GST series are transformed to 15 -year averages that coincide with the time steps of the pseudo-reconstructed inversions over the time interval considered. Trends are then calculated by subtracting the mean values of the last and first 15 -year steps and dividing the result by the total length of the reference time interval. This allows for a verification of the robustness of the results. We focus on the 20th century to evaluate trends because of the following: the bulk of the warming takes place in this period; results are less sensitive to the selection of the 15 -year interval than if the 19th century is considered, due to the influence of natural (internal and forced) variability; and it offers the possibility to compare results with instrumental trends (Hartmann et al., 2013). Thus, Fig. $2 \mathrm{~b}$ shows results for linear fit to the 1900-2005 CE period and for trends calculated from the rates of change between 1890-1905 and 1990-2005 CE (15year-diff in Fig. 2b). Figure 2b shows the frequency distribution of trends calculated from both approaches for all members within the ALL- $F$ ensemble. Box-and-whisker plots are shown for all possible scenarios considered herein, which include the following: GST, IBS $_{\mathrm{L} 12}$, GST masked with the realistic borehole configuration in space and time ( $\left.\mathrm{GST}_{\text {mask }}\right)$, $B_{\text {mask }}$ as well as the differences among them $\left(\mathrm{IBS}_{\mathrm{L} 12}-\mathrm{GST}\right.$, $B_{\text {mask }}-\mathrm{GST}_{\text {mask }}$, GST $-\mathrm{GST}_{\text {mask }}$ and $\mathrm{IBS}_{\mathrm{L} 12}-B_{\text {mask }}$ ). In the case of the $B_{\text {mask }}$ series, the trend estimation considers the time interval from 1900 to the last available date.

Interestingly, the frequency distribution of trends within the ALL- $F$ ensemble is similar for both strategies (15-yeardiff and linear fit). The estimated global trends (GST in 
(a)
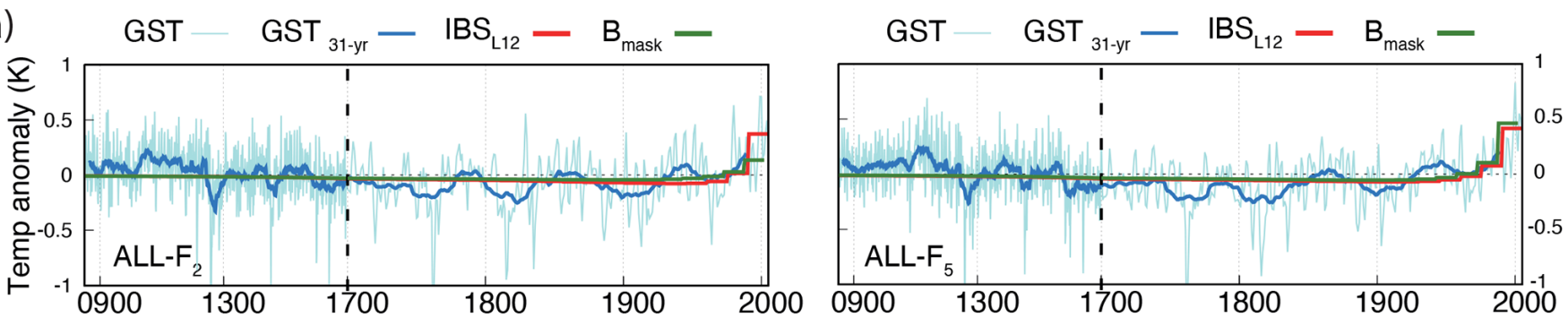

(b)
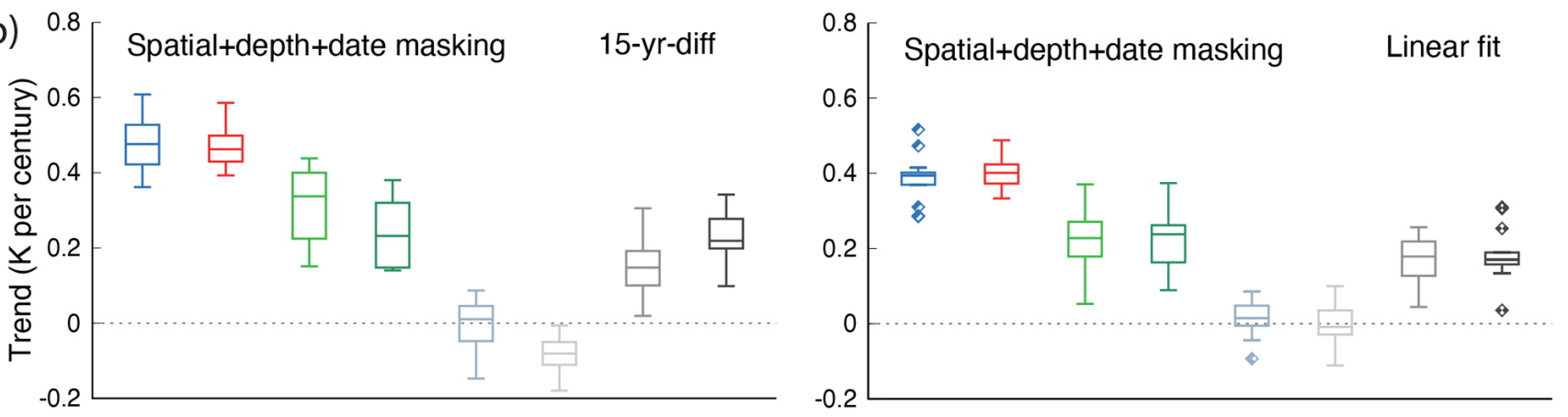

(c)
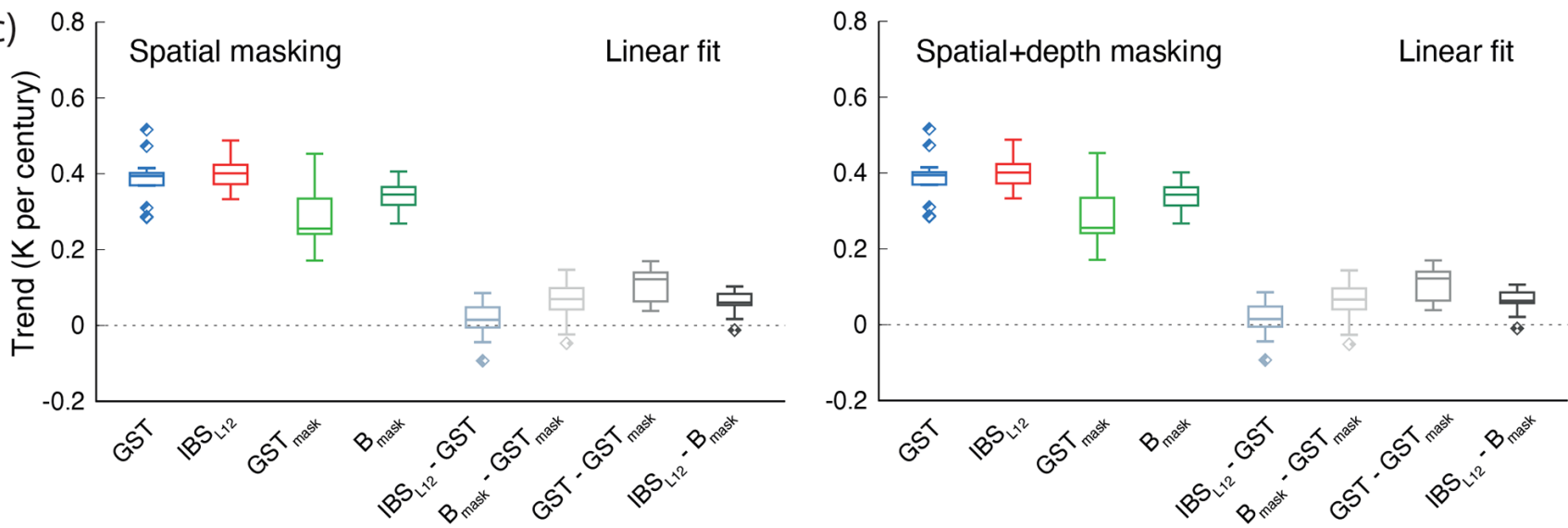

Figure 2. (a) LM global GST annual anomalies and the corresponding 31 -year filtered output and the global IBS $\mathrm{L}_{\mathrm{L} 2}$ and $B_{\text {mask }}$ pseudoreconstructions for the ALL- $F_{2}$ and ALL- $F_{5}$ members of the ALL- $F$ ensemble. Note the different discretization in the $x$ axis after 1700 CE. (b) Boxplots describing the centennial trends over the period 1900-2005 CE, calculated for each of the 13 ensemble members within ALL- $F$ after applying space, depth and time masking in the model to mimic real BTP distribution. Boxplots of trend differences have been created by subtracting individual trends, following Santer et al. (2008). Panel (c) as in (b) but applying spatial and depth masking (right) and only spatial masking (left). GST, IBS $\mathrm{L}_{12}, \mathrm{GST}_{\text {mask }}, B_{\text {mask }}$ and the differences between $\mathrm{IBS}_{\mathrm{L} 12}-\mathrm{GST}, B_{\text {mask }}-\mathrm{GST}_{\text {mask }}$, GST $-\mathrm{GST}_{\text {mask }}$ and IBS $_{\mathrm{L} 12}-B_{\text {mask }}$ cases are represented. Trends are presented as the 15-year-difference case (b left; see text) and the linear fit to the data calculated over an annual basis (b right). The 25th, 50th and 75th percentiles are indicated, and the whiskers represent the lowest/highest value within 1.5 interquartile range (IQR) of the 25 th/75th percentile. Outliers are indicated as diamonds in the same color of the box. They represent the values lower/higher than the lower/upper whisker. Note that colors in (a) correspond with those in (b) and (c).

Fig. 2b) show statistically significant values $(p<0.05)$ that range between 0.3 and $0.6 \mathrm{~K}$ per century across the 13 simulations. Thus, internal variability has an impact on these trends estimates. The significance of the trends is based on a $t$ test and accounts for the temporal autocorrelation by using a lag-1 autoregressive statistical model, based on standard procedures for temperature time series (Santer et al., 2008; Hartmann et al., 2013). Likewise, autocorrelation is also accounted for in the estimation of the reduced degrees of freedom (Storch and Zwiers, 1999). The trend values are somewhat smaller than those of the observational record, which range between 0.73 and $0.83 \mathrm{~K}$ per century over the 1901-2012 CE period for the global mean surface temperature (Hartmann et al., 2013). In both cases, the $\mathrm{IBS}_{\mathrm{L} 12}$ pseudo-reconstruction yields a reasonable estimation of the global GST increase during the 20th century. Note that the GST trends are slightly larger for the 15-year-difference case (15-year-diff) relative to the linear fit. While the lin- 
ear trend indicates a median GST increase of 0.39 , the 15 year-diff suggests a median of $0.47 \mathrm{~K}$ per century. Nevertheless, the IBS $\mathrm{L}_{\mathrm{L} 2}-\mathrm{GST}$ differences are distributed around zero in either case (Fig. 2b). The comparison of the two methods to estimate the 20th-century temperature increase shows that in either case, the pseudo-reconstructed GSTs robustly represent the targeted temperature signal. It is remarkable that when GSTs are masked, i.e., sampled, in space and time (GST $\mathrm{Gask}_{\text {ma }}$ ) following the real distribution, trends take a smaller range of values than those of GST. GST - GST mask differences are above 0 and can reach $0.3 \mathrm{~K}$ per century; thus they are significant and important in the context of the simulated warming. The significance test $(p<0.05)$ of trend differences is based on a "paired trends" test following Santer et al. (2008) and also accounts for temporal autocorrelation. It is remarkable how the level of impact may depend on the interplay of internal variability and BTP sampling. Additionally, the pseudo-reconstructions $B_{\text {mask }}$ correspondingly deliver a distribution of trends that agrees in range with those

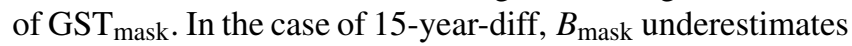
slightly, with $B_{\text {mask }}-\mathrm{GST}_{\text {mask }}$ distributed slightly below 0 , whereas in the linear case $B_{\text {mask }}-\mathrm{GST}_{\text {mask }}$ differences are centered at zero.

Therefore, the borehole reconstructions are able to retrieve the masked or unmasked GST. However, sampling plays a role and can produce an underestimation of GSTs. This underestimation depends on the interplay between sampling and internal variability and occurs in some simulations in which for the selected points, their depths and logging dates are not optimal to represent global warming. Note that in Fig. $2 \mathrm{~b} B_{\text {mask }}$ actually includes the effects of masking, i.e., selecting, pseudo-BTPs colocated with the actual BTP network, trimmed to their actual depths in reality and generated using GST histories up to their logging dates. In turn, $\mathrm{GST}_{\text {mask }}$ includes the effects of masking, i.e., selecting in this case the grid-point time series colocated with actual BTP locations and trimmed to their logging dates; depth masking does not play a role in the case of GST series.

At this point, the question of what the relative role of each of the three masking effects is remains. Figure $2 \mathrm{c}$ addresses this by showing plots similar to the linear fit in Fig. 2b but considering only spatial and spatial plus depth masking. Note that even if the masked version is still referenced only as $\operatorname{GST}_{\text {mask }}\left(B_{\text {mask }}\right)$ in the $x$ axis, in Fig. 2c left (right) the masking includes only spatial (spatial+depth) masking. The results for GST, IBS $\mathrm{L}_{12}$ and $\mathrm{IBS}_{\mathrm{L} 12}-\mathrm{GST}$ differences are shown in a way that is identical to Fig. 2b, right, for comparison. Results are virtually the same for both plots in Fig. 2c. This implies that the effects of depth masking are negligible. Nonetheless, this may not be the case in real-world BTPs of different depths because the elimination of the background geothermal gradient to obtain the anomaly profiles is done by linear fitting at the bottom of the profile (Beltrami et al., 2011, 2015), thus introducing a source of uncertainty that has not yet been considered in PPE approaches. Spatial masking does have an impact, albeit smaller than if the effects of logging dates are considered, with GST - GST mask $_{\text {differences }}$ above 0 and below $0.2 \mathrm{~K}$ per century. $\mathrm{IBS}_{\mathrm{L} 12}$ and $B_{\text {mask }}$ are effective in retaining their targets.

The selection of the number of singular values to be retained in SVD inversion may also exert some influence on the estimation of the GST recent trends. Therefore, the impact on reconstructed GST trends of including four and five PCs has been analyzed. The latter is illustrated in Fig. S1 of the Supplement. On the one hand, the solution considering the four leading modes yields similar estimations as the solution based on the three leading modes. Nonetheless, the four-PC $\mathrm{IBS}_{\mathrm{L} 12}$ solution is slightly biased toward larger values (Fig. S1a). Such behavior is also present in the $B_{\text {mask }}$ configuration relative to the $\mathrm{GST}_{\text {mask }}$. This pattern is systematically observed in all members of the ALL- $F$ ensemble as indicated in the box-and-whisker plot in Fig. S1a. Note the positively biased $\mathrm{IBS}_{\mathrm{L} 12}-\mathrm{GST}$ and $B_{\text {mask }}-\mathrm{GST}_{\text {mask }}$. On the other hand, the results including the five leading modes yield a solution with some increase in the variance (Beltrami and Mareschal, 1995), noticeable within the 20th century. The simulated GST 20th-century trends are biased toward smaller values in comparison to those in Fig. $2 \mathrm{~b}$; they are systematically underestimated by the five-PC IBS $_{\mathrm{L} 12}$ solution (Fig. S1b). In real-world data, the level of noise in BTPs limits the number of retained principal components (Beltrami and Bourlon, 2004). We have used here a conservative low value that may be consistent with real-world applications including noise.

The hemispheric to global borehole reconstructions in the real-world conditions are far from the idealized scenario described by $\mathrm{IBS}_{\mathrm{L} 12}$ since they are the result of an aggregation of a limited number of BTPs that are sparsely distributed over the land surface. Further, there is a large variability in both depth and timing in the records since BTPs are obtained from different sources, and they are rarely drilled for the development of climate studies (Jaume-Santero et al., 2016).

The global GST increase during industrial times is, however, underestimated by the $B_{\text {mask }}$ scenario. This feature is common to all ensemble members within the ALL- $F$ pool of simulations given the median $\mathrm{IBS}_{\mathrm{L} 12}-B_{\text {mask }}$ difference of $0.17 \mathrm{~K}$ per century (Fig. 2b), which accounts for about $43 \%$ of the simulated global GST 20th-century warming. Most of this underestimation is due to temporal masking. Almost half of the grid points containing BTPs in the $B_{\text {mask }}$ case are dated prior to $1982 \mathrm{CE}$, and only $\sim 5 \%$ of them present logging dates after 1995 CE (Fig. 1a). As a consequence, many of the synthetic BTPs do not include information from the last 2 decades of the simulated period, leading to a muted estimation of the global GST recent trend (Pollack and Smerdon, 2004). The variability in the depth of the borehole records, on the other hand, has no influence on the results of the $B_{\text {mask }}$ configuration. This is because only BTPs deeper than $200 \mathrm{~m}$ have been retained. This is a depth that has been shown to be sufficient to capture the trend estimates 
from the LIA to present days and to even retain some features of the MCA to the LIA transition. Likewise, the spatial distribution of the borehole records has a smaller influence on the $B_{\text {mask }}$ trends at hemispheric to global scales, as indicated in both real-world borehole reconstructions (Pollack and Smerdon, 2004; Beltrami and Bourlon, 2004) and PPEs (González-Rouco et al., 2006).

In spite of the general pattern of discrepancies between $B_{\text {mask }}$ and $\mathrm{IBS}_{\mathrm{L} 12}$ during the industrial period (e.g., ALL- $F_{2}$; Fig. 2a), there are also cases in which both estimates show a good agreement (e.g., ALL- $F_{5}$ ). This range of variability in the representation of the 20th-century trends indicates that the internal climate variability within each realization exerts some influence on the simulated trends of the $B_{\text {mask }}$ configuration. As the global average for the last 2 decades highly depends on the most recently logged BTPs, mostly concentrated in northern Canada, central Europe, Russia and Japan (Fig. 1a), the internal climatic responses over these regions apparently play a significant role in the global 20thcentury trend estimations. Nevertheless, it would be desirable to expand and update the current dataset of BTPs. In the meantime, it seems advisable to derive strategies that minimize the impact of aging in BTPs (Harris and Chapman, 2001), perhaps by blending BTP information and instrumental temperature observations from the last few decades or using other procedures that reduce underestimation of multidecadal trends during this period.

The variability in the spatiotemporal distribution of the borehole network may impact the representation of the past GST evolution from BTPs at smaller spatial scales. In order to explore this, three subcontinental domains with different levels of BTP coverage have been selected. These domains include regions over North America, Europe and Africa. Their selection intends to be illustrative of sampling effects by broadly including existing BTPs in each domain without, however, necessarily representing optimized domain configurations in any sense. The GST annual anomalies for these regions and their corresponding 31-year (running mean) low-pass filter outputs, $\mathrm{IBS}_{\mathrm{L} 12}$ and $B_{\text {mask }}$, estimates cases are shown for one member of the ALL- $F$ ensemble as an example for each of the regions (Fig. 3 center). ALL- $F_{2}$ is presented for North America (Fig. 3a) while ALL$F_{3}$ is shown for both Europe (Fig. 3b) and Africa (Fig. 3c) as these members are representative of the mean behavior of the $B_{\text {mask }}$ configuration within the ALL- $F$ ensemble. The boxand-whisker plots (Fig. 3 right) show the 20th-century trends from the 13 members of the ensemble as in Fig. 2b, using the linear regression.

Interestingly, the results of the $\mathrm{IBS}_{\mathrm{L} 12}$ and the $B_{\text {mask }}$ configurations show better agreement over the better-sampled area of North America than over Europe and Africa. This is evident in the representation of the 20th-century trends, with a difference in their corresponding median value of around $0.08 \mathrm{~K}$ per century in North America. Masking produces differences (GST $-\mathrm{GST}_{\text {mask }}$ and $\mathrm{IBS}_{\mathrm{L} 12}-B_{\text {mask }}$ in Fig. 3) that range from 0 to $0.2 \mathrm{~K}$ per century, thus suggesting underestimation biases. The bias is reduced when spatial-only masking is considered (Fig. 4), although some outliers still produce GST - GST mask differences above $0.1 \mathrm{~K}$ per century. The size of those differences is not large, but it represents between $20 \%$ and $30 \%$ of the simulated trends.

The results for Europe and Africa are more variable. GST trends center around $0.4 \mathrm{~K}$ per century in North America and Europe and below $0.1 \mathrm{~K}$ per century in the African domain considered (Fig. 3). However, trends at these spatial scales can be highly dependent on internal variability, and some simulations show no significant trends over the European and African domains. Additionally, poor spatial sampling enhances the influence of local behavior since only few grid points, often distributed within a relatively small area, determine the average of the whole region. Note that the representation of the 20th-century trends in both GST $_{\text {mask }}$ and $B_{\text {mask }}$ spreads over a larger range in Europe and especially in the African region compared to North America. This happens as a response to a decline in the availability of recent BTPs for calculating the regional averages during the last few decades of the simulated period (see the maps in Fig. 3). In Europe, the $B_{\text {mask }}$ configuration systematically underestimates the IBS $\mathrm{L}_{12}$ results, but there are cases (not shown) in which the results of the $B_{\text {mask }}$ case closely match the ideal scenario. Thus, these differences among estimates from the different ensemble members suggest an influence from the internal variability on the estimations of the recent temperature trends. Over the African continent, the estimates are more diverse. Therein, the difference between $\mathrm{IBS}_{\mathrm{L} 12}$ and $B_{\text {mask }}$ depicts a larger variability, with a general poor representation of the 20th-century GST increase over this region.

When only spatial masking is considered, the spread of the results is reduced for all regions. For the European domain, most of the solutions of GST $-\mathrm{GST}_{\text {mask }}\left(\mathrm{IBS}_{\mathrm{L} 12}-B_{\text {mask }}\right)$ get confined below $+0.1(-0.1) \mathrm{K}$ per century (Fig. 4). For the African domain, the dispersion in GST - GST mask and $\mathrm{IBS}_{\mathrm{L} 12}-B_{\text {mask }}$ also shrinks, with both cases indicating overestimation that can be larger than $0.3 \mathrm{~K}$ per century when spatial masking only (Fig. 4) is considered; i.e., the selected grid points indicate larger warming than the rest of the regions. The selected case examples in Fig. 3 (center) illustrate how different the unmasked IBS $_{\mathrm{L} 12}$ and the $B_{\text {mask }}$ solutions can be, both in representing the warming of the last few decades of the 20th century and also the cooling during the 19th and early 20th century. The latter is most noticeable in the example shown for Europe in which clear differences develop during the 19th century between $\mathrm{IBS}_{\mathrm{L} 12}$ and $B_{\text {mask }}$. Here, spatial sampling misses the cooling shown by $\mathrm{IBS}_{\mathrm{L} 12}$. The reasons for that are discussed in Sect. 4.2.

Therefore, the 20th-century $B_{\text {mask }}$ trends are sensitive to the spatiotemporal distribution of the borehole network, particularly at smaller scales. Whereas in the North American continent there is a better coverage of borehole logs, including most of those recently recorded, in Europe and especially 

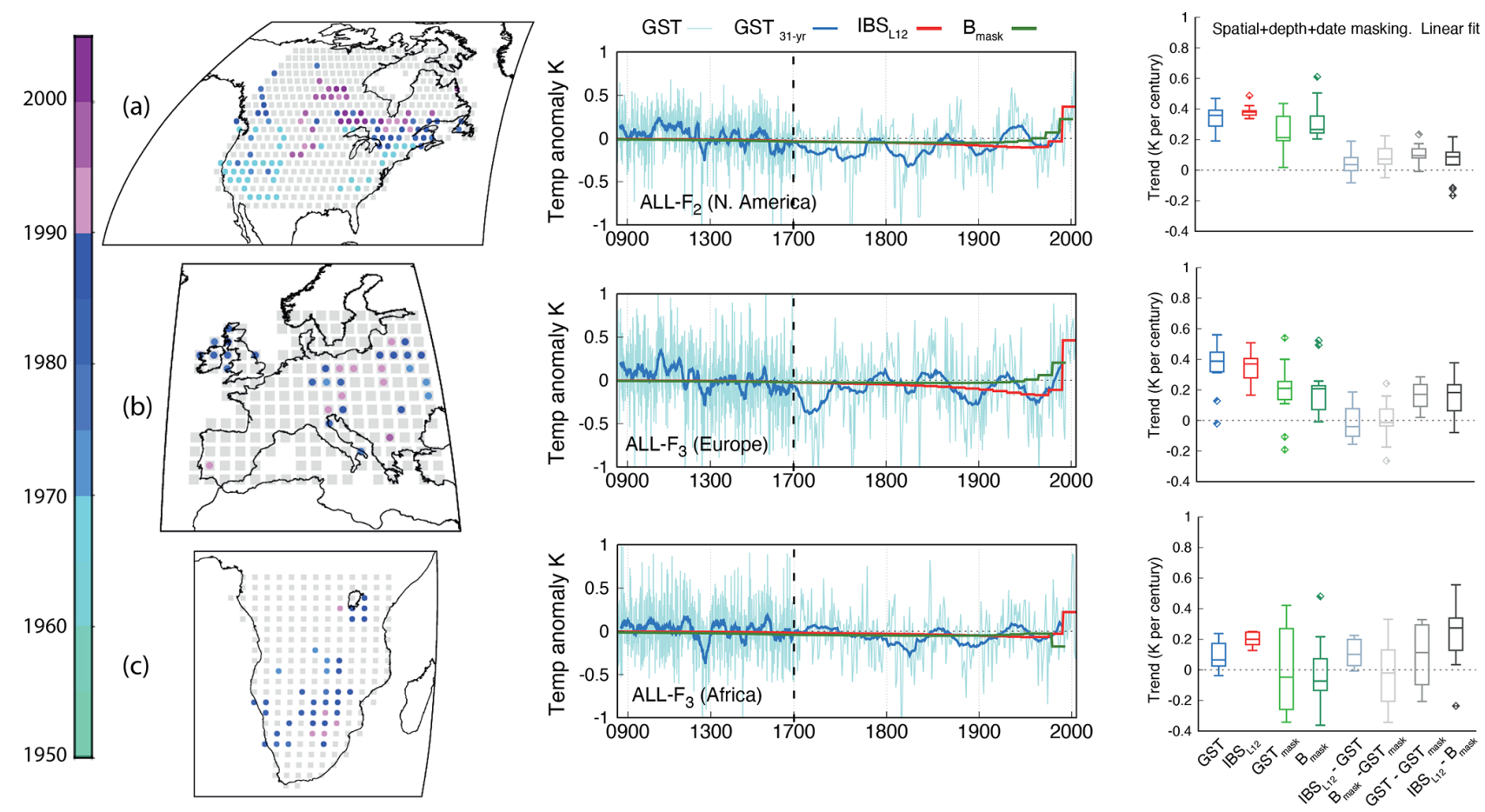

Figure 3. LM global GST annual anomalies and pseudo-reconstructions for three different subcontinental regions: (a) North America (31.26$\left.69.16^{\circ} \mathrm{N}, 135-55^{\circ} \mathrm{W}\right)$, (b) Europe $\left(36.59-59.68^{\circ} \mathrm{N}, 10^{\circ} \mathrm{W}-30^{\circ} \mathrm{E}\right)$ and (c) Africa $\left(35.05^{\circ} \mathrm{S}-2.28^{\circ} \mathrm{N}, 10-40^{\circ} \mathrm{E}\right)$. The ALL- $F_{2}$ member is displayed for the North American continent, whereas the ALL- $F_{3}$ member of the ALL-F ensemble is used for the European and African regions. Maps in (a)-(c) show the spatial distribution of BTP locations and dates of the actual borehole network for each of the regions. Grey dots show the model grid and the areas defining each of the regions. Right panels: as in Fig. 2a and b but with the 1900-2005 CE trends presented for only the linear fit method.
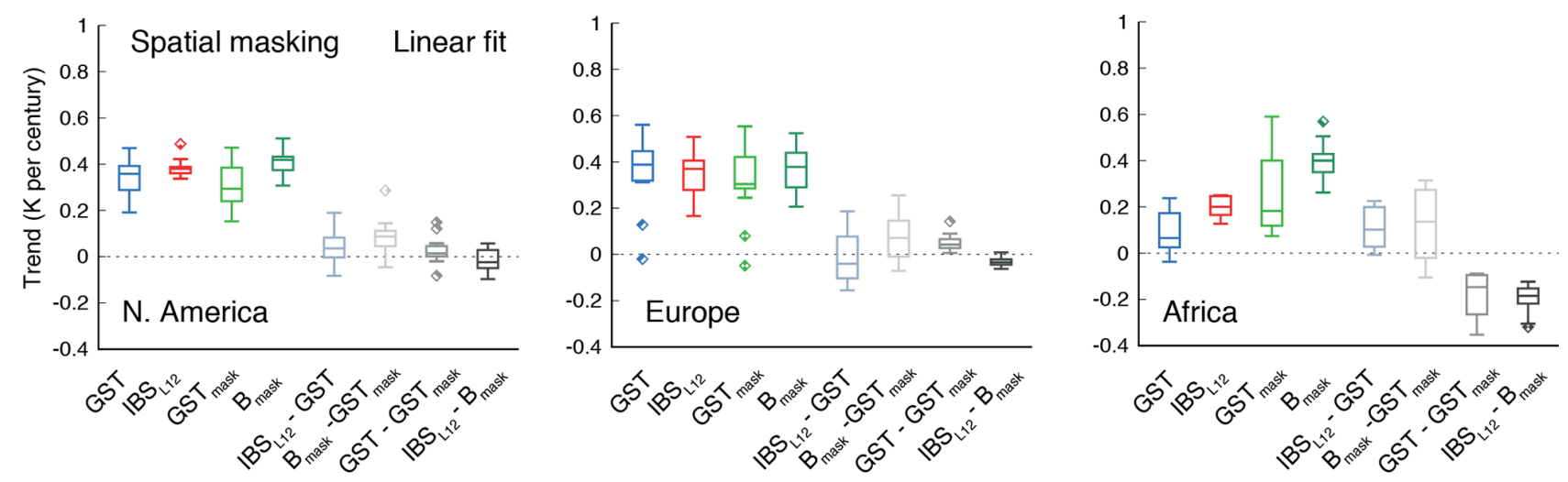

Figure 4. As in Fig. 3 (right) but with the masked cases (i.e., GST mask or $B_{\text {mask }}$ ) including only spatial masking. Linear fit estimated 1900 2005 CE trends in the ALL- $F$ ensemble for North American, European and African regions shown in Fig. 3. Abbreviations for GST and PPE cases and their differences follow the same convention as in Figs. 2 and 3.

in Africa, there are comparatively poorer representations and inhomogeneous spatial distributions of BTPs, particularly of the recent ones, that ultimately impact the resulting temperature trend estimates. This suggests that the interpretation of the trends from borehole reconstruction estimations at the regional scale should be done with caution over areas with poor spatiotemporal coverage of BTPs (Huang et al., 2000).

\subsection{Biases of past SAT borehole-based reconstructions due to physical processes}

In addition to the limitations imposed by the spatiotemporal borehole distribution, the reconstructed SAT can also be biased by changes in the long-term SAT-GST relationship. Specifically, changes in anthropogenic forcing after $1850 \mathrm{CE}$ 
(a)

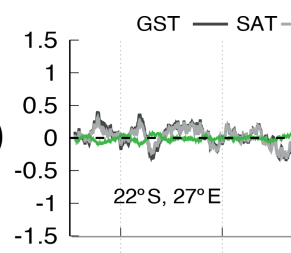

(b)

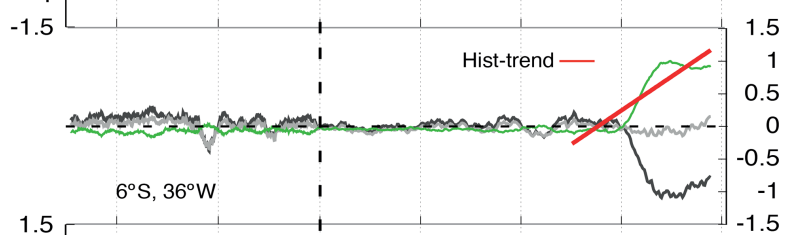

(c)

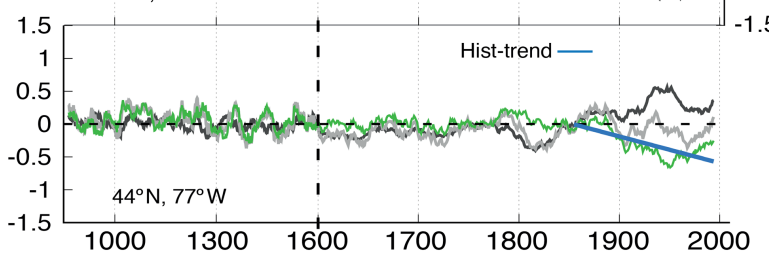

(d)

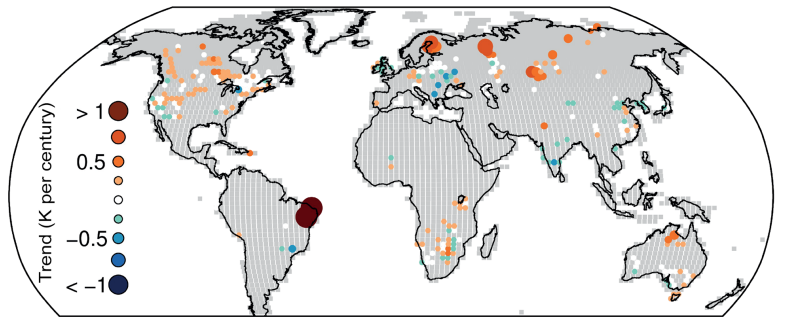

Figure 5. LM evolution of SAT and GST anomalies, SAT minus GST, and the linear trends of SAT minus GST over the 18502005 CE period for three different grid points with borehole records in ALL- $F_{2}$ as an example. Each grid point illustrates a possible case of the long-term SAT-GST relationship: (a) strong coupling during the LM, (b) decreasing GST relative to SAT and (c) increasing GST relative to SAT during industrial times. (d) Spatial distribution of linear trends in SAT minus GST anomalies over the 1850-2005 CE period evaluated at every grid point with the presence of a borehole site using the ALL- $F$ ensemble mean. Grid points showing statistically significant trends $(p<0.05)$ are colored in red/blue depending on whether they are increasing/decreasing SAT-GST trends.

can contribute to SAT-GST decoupling (Melo-Aguilar et al., 2018).

Figure 5a-c show the LM evolution of SAT and GST anomalies relative to the $850-2005$ CE mean, as well as the difference between them, and the linear trend of SAT - GST for the period 1850-2005 CE at selected grid points, illustrating three possible behaviors of the long-term SAT-GST relationship in the CESM-LME. First, there is a case in which this relationship remains stable during the whole LM (Fig. 5a). Note that there is no trend in the SAT - GST differences. This case represents the ideal strong SAT-GST coupling situation from which the GST would constitute a good proxy of the SAT. Second, two different cases in which the SAT-GST long-term relationship experiences significant variations are depicted. The direction and magnitude of the SAT minus GST trend are suggestive of the type of impact had on the SAT-GST coupling. In the first case (Fig. 5b), the sharp decrease in GST around $1900 \mathrm{CE}$ results in a positive trend in the SAT - GST differences of $1.04 \mathrm{~K}$ per century, which is represented in red, indicating a warmer SAT relative to the GST. The second one (Fig. 5c) depicts an example in which the SAT tends to be colder than GST during the industrial period, thus leading to a negative trend of about $-0.4 \mathrm{~K}$ per century (blue). These two cases are suggestive of a physical interference affecting the temperature signal contained in the subsurface. Therefore, the inversion of BTPs under such characteristics would yield unreliable information of the past SAT variations. The ALL- $F_{2}$ simulation is used as an example, but similar results can be found in other ALL- $F$ ensemble members.

To provide a spatial view of the borehole locations affected by changes in the long-term SAT-GST relationship in the CESM-LME world, we evaluate the SAT minus GST industrial (1850-2005 CE) trends for the ALL- $F$ ensemble mean at every grid point with the presence of a borehole (Fig. 5d). The ensemble mean is used in order to identify the forced response; however, the internal climate variability in individual ensemble members may result in a different representation of both the magnitude and sign of the trends (MeloAguilar et al., 2018). Since the industrial period is affected by pronounced temperature trends due to the anthropogenic emissions of GHGs, the 1850-2005 CE interval is the most adequate one to use for evaluating the particularities of the SAT-GST linear trends. Additionally, the analysis in this part is intended to determine the reliability of the borehole technique for retrieving the SAT increase over the industrial period. Figure $5 \mathrm{~d}$ illustrates that at a large number of grid points containing BTPs, the SAT minus GST linear trends are statistically significant $(p<0.05)$, identifying therefore some level of SAT-GST decoupling during the industrial period at such locations. These grid points are represented in red (blue) if the trend of the temperature differences is positive (negative). Additionally, the sizes of the circles are related to the magnitude of the trend. Therefore, both color and size indicate the direction and magnitude of the SATGST decoupling. Note that positive trends are dominant, with some larger values in northeastern Brazil, Fennoscandia, central Eurasia and northern Siberia. Negative values are also evident, mostly distributed around central and eastern Europe, with some more isolated cases distributed around the globe.

In order to assess the influence of the detected long-term SAT-GST decoupling on the representation of SAT from the borehole-based reconstructions at the global scale, results of the SAT and GST trends and their IBS pseudoreconstructions, as well as the $B_{\text {mask }}$ case including the effects of sampling, are shown in Fig. 6, together with the ALL- $F_{2}$ and ALL- $F_{5}$ ensemble members as an example. In both of them, the simulated SAT low-frequency variations over the LM are broadly reproduced by $\mathrm{IBS}_{\mathrm{SAT}}$. Note that the simulated SAT 20th-century trend is accurately captured

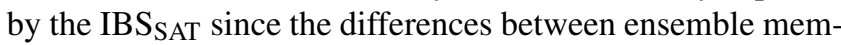
ber trends are distributed around zero (Fig. 6b). Therefore, 

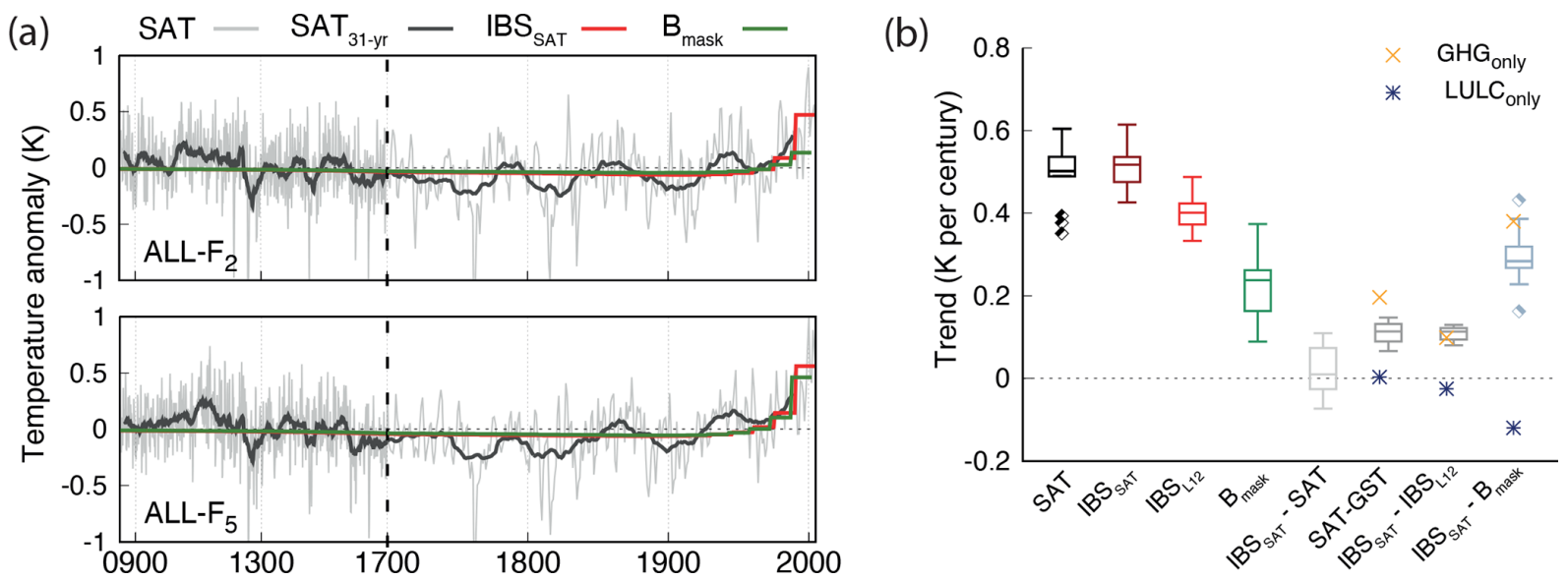

Figure 6. (a) LM global SAT annual anomalies and the corresponding 31-year filtered outputs and the global IBS $\mathrm{SAT}$ and $B_{\text {mask }}$ pseudoreconstructions for the ALL- $F_{2}$ and ALL- $F_{5}$ members of the ALL- $F$ ensemble. Note the different discretization in the $x$ axis after 1700 CE. (b) Estimated linear fit as Fig. 2b, but the SAT, IBS $\mathrm{SAT}, \mathrm{IBS}_{\mathrm{L} 12}, B_{\text {mask }}$ and the differences between IBS $\mathrm{SAT}-\mathrm{SAT}$, SAT $-\mathrm{GST}_{\text {, IBS }} \mathrm{SAT}-$ $\mathrm{IBS}_{\mathrm{L} 12}$ and $\mathrm{IBS}_{\mathrm{SAT}}-B_{\text {mask }}$ cases are represented. Additionally, the ensemble medians of the GHG- and LULC-only ensembles are indicated by the crosses and asterisks, respectively, in the $\mathrm{IBS}_{\mathrm{SAT}}-\mathrm{IBS}_{\mathrm{L} 12}$ and the $\mathrm{IBS}_{\mathrm{SAT}}-B_{\text {mask }}$ columns.

IBS $_{\text {SAT }}$ can be considered a reasonable representation of the simulated SAT, specifically in the estimation of the 20thcentury warming. Thus, the comparison between IBS $_{\mathrm{SAT}}$ and $\mathrm{IBS}_{\mathrm{L} 12}$ will be informative about any deviation between the pseudo-reconstructed GST and the simulated SAT.

Indeed, SAT - GST trend differences are distributed over a median value of $0.1 \mathrm{~K}$ per century, and consistently, the 20th-century $\mathrm{IBS}_{\mathrm{SAT}}-\mathrm{IBS}_{\mathrm{L} 12}$ trend differences yield positive values, with a median of about $0.11 \mathrm{~K}$ per century and a high level of agreement, i.e., small dispersion, among the members of the ALL- $F$ ensemble (Fig. 6b). This indicates that even under an ideal scenario, the pseudo-reconstructed GST does not fully capture the 20th-century SAT warming, missing on average $\sim 20 \%$ of the simulated SAT increase in the CESM-LME as a response to the long-term SAT-GST decoupling. Furthermore, the effect of the physical processes is superimposed on the limitations due to the methodological aspects, leading to larger differences with respect to the more realistic pseudo-reconstructed GST $\left(B_{\text {mask }}\right)$. In fact, the $\mathrm{IBS}_{\mathrm{SAT}}-B_{\text {mask }} 20$ th-century trend differences have a median of $0.28 \mathrm{~K}$ per century (Fig. $6 \mathrm{~b}$ ), which represents more than $50 \%$ of the simulated SAT trend. There is, however, a larger variability in trend differences between these two scenarios, which ranges between 0.16 and $0.43 \mathrm{~K}$ per century. This spread results from the internal climate variability in each realization of the ensemble. Such a range of variability is noticeable in Fig. 6a if IBS $\mathrm{IAT}_{\mathrm{SAT}}$ and $B_{\text {mask }}$ trends for the two ensemble members are compared to each other.

Melo-Aguilar et al. (2018) showed that the long-term SAT-GST decoupling in the CESM-LME is mainly driven by LULC and GHG changes. LULC changes modify the radiative fluxes at the surface, leading to a different response of the SAT and GST. Likewise, the SAT increase during industrial times as a response to the increase in GHGs may not be fully transferred to the soil due to the insulating effect of snow cover feedbacks. To explore their effects on borehole reconstructions, the analysis described in Fig. 5d is extended to the GHG- and LULC-only ensembles (Fig. 7a). In the GHG-only ensemble (Fig. 7a left) the dominant effect is represented by positive SAT minus GST trends, with a similar pattern to the ALL- $F$ ensemble over North America, Fennoscandia, northern Russia and Siberia in Fig. 5d, although the magnitude of the trends is significantly larger. On the contrary, in the LULC-only ensemble negative SAT minus GST estimates are evident, indicating a similar response as in the ALL- $F$ ensemble over central and eastern Europe and the Indian subcontinent (Fig. 5d). Additionally, the strong positive trends over northeastern Brazil resemble those found in the ALL- $F$ ensemble.

The IBS $\mathrm{IAT}_{\mathrm{SA}}, \mathrm{IBS}_{\mathrm{L} 12}$ and $B_{\text {mask }}$ configurations are also implemented in the GHG- and LULC-only ensembles in order to evaluate their contributions to the physical SATGST decoupling at the global scale. Figure $7 \mathrm{~b}$ compares the simulated global SAT anomalies with the IBS $\mathrm{SAT}_{\mathrm{SA}}$ and the $B_{\text {mask }}$ pseudo-reconstructions in the $\mathrm{GHG}_{1}$ (Fig. $7 \mathrm{~b}$ left) and LULC $_{1}$ (Fig. 7b right) members of the GHG- and LULConly ensembles, respectively, as an example. From a simple visual inspection it may be noticed that the $\mathrm{GHG}_{1}$ simulation portrays a response similar to the ALL- $F$ estimates (Fig. 6a) since the IBS $\mathrm{IAT}_{\mathrm{SA}}$ and the $B_{\text {mask }}$ cases diverge during the last few decades of the simulated period. On the other hand, in the LULC $_{1}$ case (Fig. $7 \mathrm{~b}$ right), there is no such similarity to the ALL- $F$ cases. All series and pseudo-reconstructions suggest a consistent cooling in response to LULC changes throughout the last few centuries of the millennium. This analysis suggests a larger contribution of the GHG forcing 

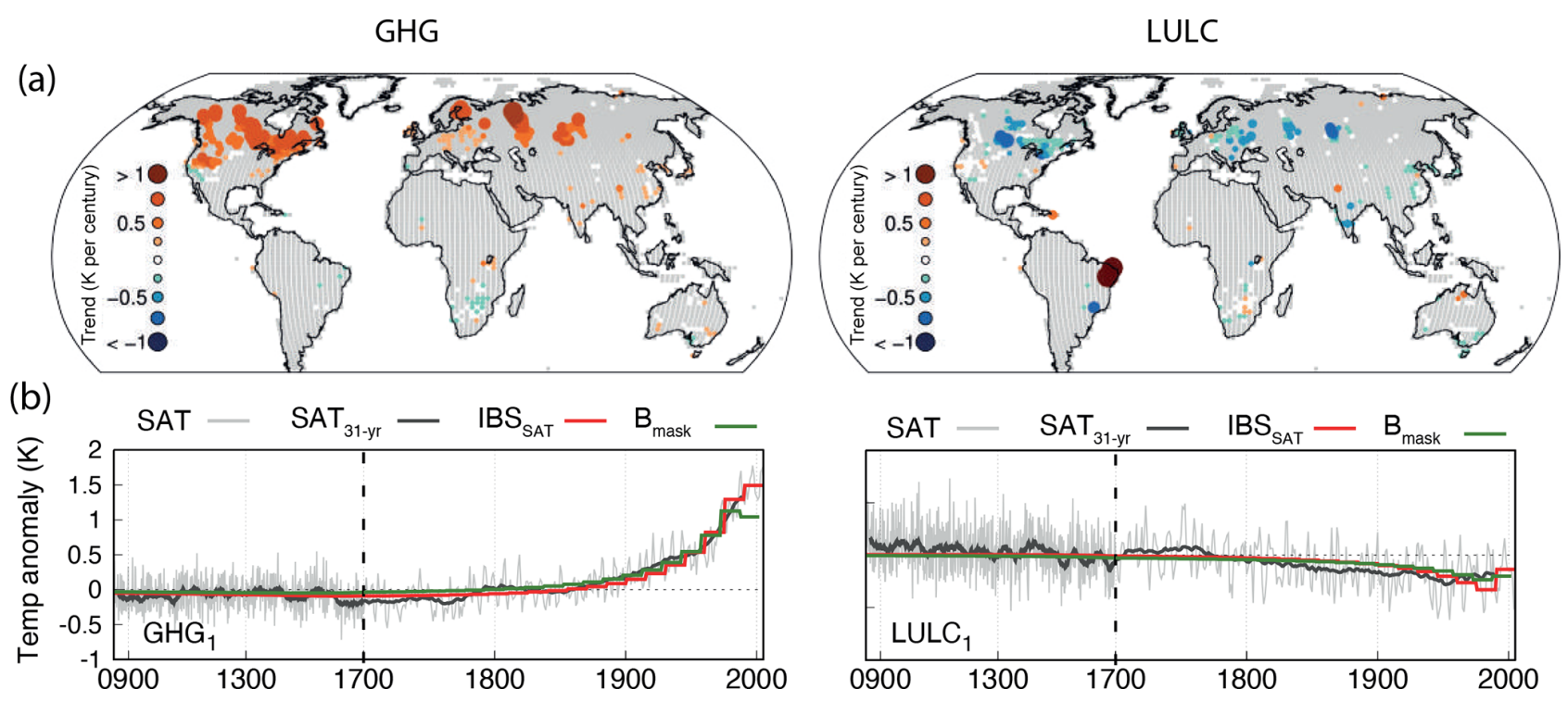

Figure 7. (a) Spatial distribution of linear trends in SAT - GST anomalies over the 1850-2005 CE period evaluated at every grid point colocated with a borehole site in the GHG- and LULC-only ensemble mean (left and right in a, respectively). Only grid points delivering statistically significant trends $(p<0.05)$ are colored. (b) LM global SAT annual anomalies and the corresponding 31-year filtered outputs and the global $\mathrm{IBS}_{\mathrm{SAT}}$ and the $B_{\text {mask }}$ pseudo-reconstructions for the $\mathrm{GHG}_{1}$ and $\mathrm{LULC}_{1}$ ensemble members. Note the different discretization in the $x$ axis after $1700 \mathrm{CE}$.

to the SAT-GST decoupling relative to the LULC forcing at the global scale.

To provide a quantitative support for this statement, the median of the differences between the $\mathrm{IBS}_{\mathrm{SAT}}-\mathrm{IBS}_{\mathrm{L} 12}$ and $\mathrm{IBS}_{\mathrm{SAT}}-B_{\text {mask }} 20$ th-century trends in the GHG- and LULConly ensemble are included in Fig. $6 \mathrm{~b}$ (crosses and asterisks, respectively). Results are almost identical if the mean instead of the median of the single- $F$ is included. Note there that in the IBS $\mathrm{IAT}_{\mathrm{SAT}}-\mathrm{IBS}_{\mathrm{L} 12}$ case the GHG-only ensemble shows positive and very similar estimates to the median of the ALL- $F$ ensemble $(0.09$ and $0.11 \mathrm{~K}$ per century, respectively), suggesting a large contribution of the GHG forcing to the physical bias in the representation of SAT by the borehole pseudo-reconstructions in the CESM-LME at the global scale. On the contrary, in the LULC-only ensemble the $\mathrm{IBS}_{\mathrm{SAT}}-\mathrm{IBS}_{\mathrm{L} 12}$ difference is negative and very small $(-0.02 \mathrm{~K}$ per century) indicating a negligible contribution at this spatial scale. These results are in agreement, as expected, with pure SAT - GST differences, which also receive a larger contribution from GHG at these spatial scales. The $\mathrm{IBS}_{\mathrm{SAT}}-B_{\text {mask }}$ differences further highlight the larger influence of the GHG relative to the LULC forcing. Whereas in the GHG-only ensemble the median IBS $_{\mathrm{SAT}}-B_{\text {mask }}$ difference shows values trending in the same direction as the ALL$F$ ensemble, in the LULC-only ensemble the difference goes in the opposite direction (negative IBS $_{\mathrm{SAT}}-B_{\text {mask }}$ trend differences). Melo-Aguilar et al. (2018) reported that the contribution from the GHG forcing to the SAT-GST decoupling is controlled by the reduction in the $\mathrm{NH}$ winter snow cover as a response to higher temperatures during industrial times.
This situation increases the exposure of the soil surface, previously insulated by snow cover, to the cold winter air, leading to an overall effect of warmer SAT relative to GST at a global scale.

Regionally, the influence of the SAT-GST long-term decoupling on the representation of simulated SAT from the pseudo-reconstructed GST also deserves to be considered since there are geographical variations in this effect (Fig. 5d). Figure 8 illustrates SAT annual anomalies with respect to the 850-2005 CE mean and the corresponding 31-year low-pass filter outputs as well as the IBS $\mathrm{SAT}_{\mathrm{SAT}}$ and the $B_{\text {mask }}$ cases for the ALL- $F_{2}, \mathrm{GHG}_{1}$ and $\mathrm{LULC}_{1}$ simulations over the same areas described in Fig. 3. The spreads provided by considering all members of each ensemble are depicted in the boxplots at the bottom of Fig. 8. Interestingly, the decoupling effect appears to be larger over North America and Africa than over Europe. As in the case of the global average, the effect over North America and Africa is shown by the underestimation of the SAT warming during industrial times, indicated by the positive SAT - GST median differences of $\sim 0.2 \mathrm{~K}$ per century, consistent with comparable $\sim 0.2 \mathrm{~K}$ per century median change in $\mathrm{IBS}_{\mathrm{SAT}}-\mathrm{IBS}_{\mathrm{L} 12}$ that endorse the performance of the borehole method. On the contrary, in Europe, the SAT-GST decoupling leads to small differences, a negligible under- or overestimation of the SAT increase as shown by SAT-GST (IBS $\left.\mathrm{IAT}_{\mathrm{S}}-\mathrm{IBS}_{\mathrm{L} 12}\right)$.

The single- $F$ experiments indicate variability in the influence of both the GHG and LULC forcings over the different areas considered herein. In North America there is a strong contribution of the GHG forcing, which is somewhat coun- 
(a) North America

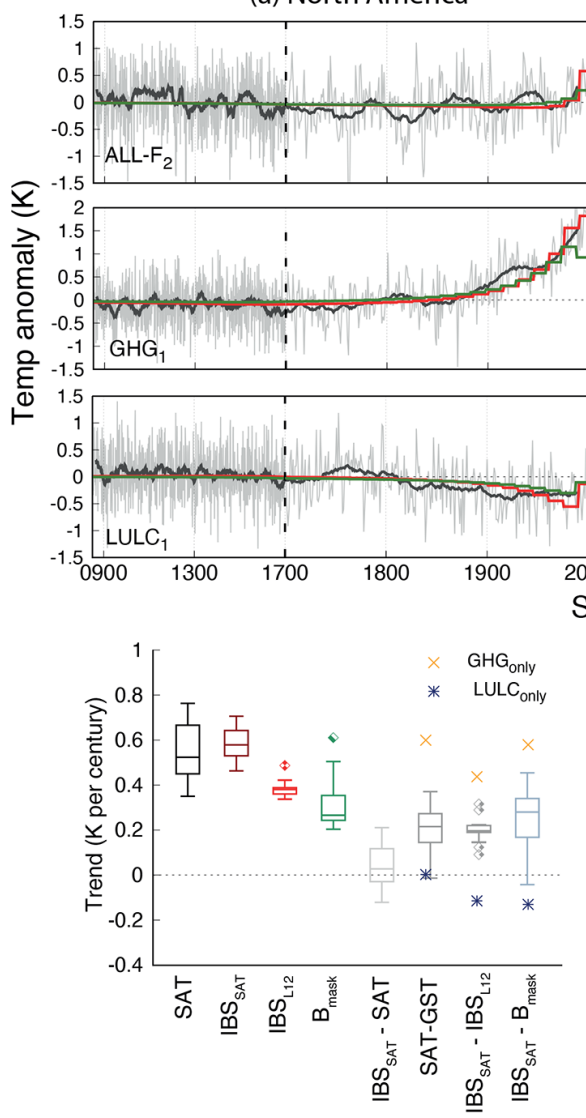

(b) Europe
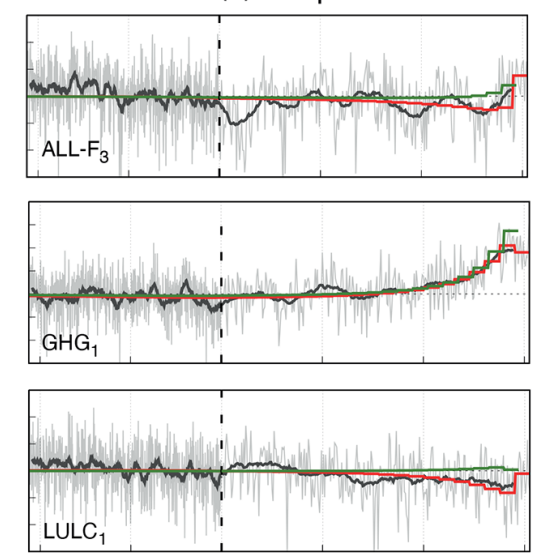

(c) Africa
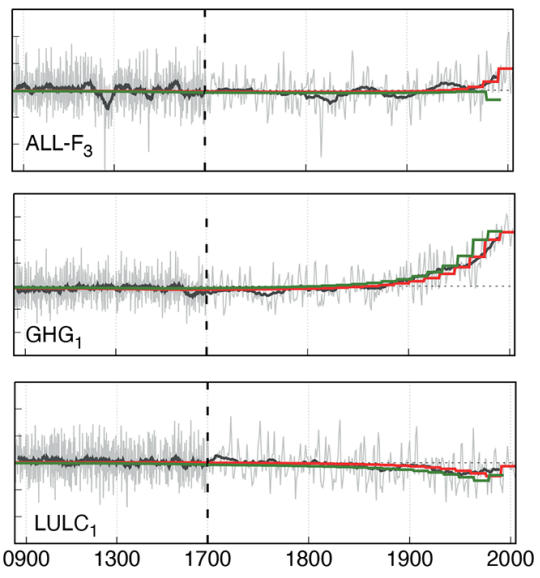
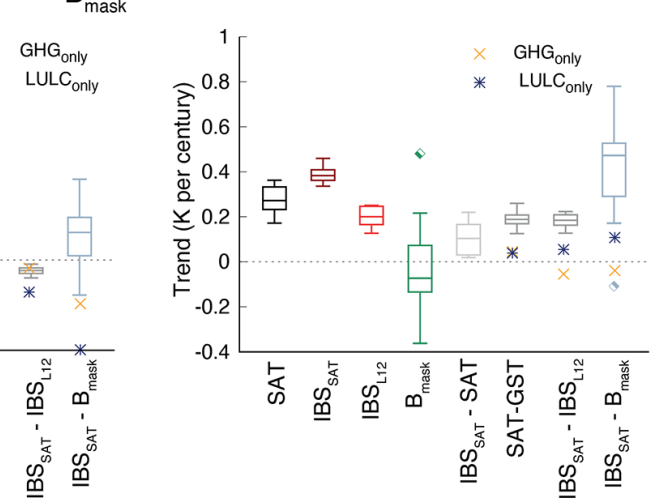

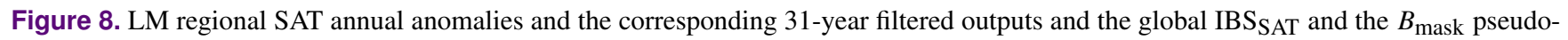
reconstructions for the ALL- $F_{2}, \mathrm{GHG}_{1}$ and $\mathrm{LULC}_{1}$ (from top to bottom) members of the ALL- $F$, GHG- and LULC-only ensembles, respectively, (a) North America, (b) Europe and (c) Africa. Note the different discretization in the $x$ axis after $1700 \mathrm{CE}$. Bottom panels as Fig. $6 \mathrm{~b}$ but for each of the regions presented.

teracted by the LULC influence. This is noticeable in not only the time series in Fig. 8a but also the sign and magnitude of the SAT - GST and the $\mathrm{IBS}_{\mathrm{SAT}}-\mathrm{IBS}_{\mathrm{L} 12}$ median difference in both the GHG- and LULC-only ensembles (Fig. 8a bottom). Conversely, over the European region, the largest contribution comes from the LULC forcing (see the larger differences in SAT - GST and $\mathrm{IBS}_{\mathrm{SAT}}-\mathrm{IBS}_{\mathrm{L} 12}$ for LULConly in Fig. 8b bottom). This is shown more clearly in the comparison of the selected examples in Fig. 8b for ALL- $F_{2}$, $\mathrm{GHG}_{1}$ and $\mathrm{LULC}_{1}$ that show that the LULC cooling dominates the long-term trends over GHG warming in the ALL$F$ experiment. For Africa, the ALL- $F$ experiment also evidences the damping of the GHG warming produced by negative LULC trends. However, other external forcings may also contribute to the response of the SAT-GST relationship at the continental scale in this region (Melo-Aguilar et al., 2018). It is also remarkable that the masked reconstruction $\left(B_{\text {mask }}\right)$ in the ALL- $F$ and LULC cases in Fig. $8 \mathrm{~b}$ does not capture the long-term cooling during the 19th and 20th centuries that is shown by the unmasked SAT averages (Fig. 8b) and GST averages (Fig. $3 \mathrm{~b}$ center). Thus, the influence of LULC forcing also explains the different trends between $\mathrm{IBS}_{\mathrm{L} 12}$ and $B_{\text {mask }}$ in Fig. $3 b$ (center) during the 19th and early 20th centuries.

The superposition of the physical biases and the methodological aspects at continental scales suggest further comments are needed. For instance, for the North American region, while the methodological constraints have a relatively reduced impact on retrieving the simulated GST 20thcentury increase in the $B_{\text {mask }}$ configuration (as discussed in Sect. 4.1), the effect of the physical processes results in a larger underestimation of the 20th-century SAT evolution. This is evident in the $\mathrm{IBS}_{\mathrm{SAT}}-B_{\text {mask }}$ difference, which has a median of $0.28 \mathrm{~K}$ per century (Fig. 8 ), representing $\sim 50 \%$ of the simulated SAT 20th-century warming. The increment can be compared with $\mathrm{IBS}_{\mathrm{L} 12}-B_{\text {mask }}$ in Fig. 3 (right). The largest contribution comes from the GHG-only forcing, partially reduced by the LULC-only effect, as shown by the single-forcing crosses in Fig. 8. Similarly, in the African region, the effects of the physical processes contribute to enhancement of the underestimation of the SAT signal by $B_{\text {mask }}$. IBS $\mathrm{SAT}_{\mathrm{SAT}}-B_{\text {mask }}$ differences expand their spread in Fig. 3, now reaching values of $0.8 \mathrm{~K}$ per century. On the 
contrary, for the European region the SAT-GST decoupling slightly counteracts the effects of the methodological aspects, mostly via negative LULC biases. However, in both of these regions, the largest contribution to a biased estimation of the 20th-century SAT trends comes from the methodological aspects (see SAT - GST and $\mathrm{IBS}_{\mathrm{L} 12}-B_{\text {mask }}$ differences in Fig. 3) that outweigh the bias from the physical processes.

\section{Conclusions}

Borehole-based reconstructions depend on two hypotheses to derive the evolution of past temperature trends. One of them is that past GST histories can be recovered from BTPs in which the conductive regime dominates; the second one is that the past GST evolution is coupled to SAT changes, and thus, the past history of SAT changes can be recovered from BTPs. The first hypothesis can be affected by methodological issues that may distort the recovery of past GSTs from BTPs, whereas the second hypothesis can be affected by physical issues that may distort SAT-GST coupling and thus the recovery of past SAT changes. This study analyses the performance of the borehole temperature reconstruction technique in a pseudo-proxy framework that allows both methodological and physical issues to be addressed.

Previous works using PPEs of borehole reconstructions have been implemented in simulations of the LM and have focused on the methodological performance at global (González-Rouco et al., 2006; García-García et al., 2016) and regional scales (González-Rouco et al., 2009), using either the output of a single climate model (González-Rouco et al., 2006, 2009) or an ensemble of PMIP3/CMIP5 LM experiments (García-García et al., 2016). We have extended the analysis of previous works by implementing PPE strategies within the ensemble of simulations of the LM produced with the CESM climate model, the so-called CESM-LME (Otto-Bliesner et al., 2016). We have updated past analyses by introducing a more realistic PPE setup to address both methodological and physical issues at global and regional scales. Additionally, the use of an ensemble of simulations with the same model and different forcing boundary conditions has allowed for the influence of internal variability and external forcings on the application of the borehole method to be considered.

The methodological implementation used herein adopts a SVD approach, as described in González-Rouco et al. (2006, 2009) and García-García et al. (2016). Similar to previous studies, the PPE has been developed in a so-called idealized scenario in which BTPs are assumed to exist at every land model grid point and are produced with a forward model using the complete set of simulated GSTs, 850-2005 CE. This is equivalent to assuming that information from BTPs is available everywhere in land and that all BTPs logs are updated to present times. In addition, more realistic scenarios considering distributions of BTPs that mimic their actual spatial, depth and logging date distributions have been constructed. The idealized scenario is used as a benchmark from which the performance of the realistic case is evaluated.

Regarding physical influences on the SAT-GST relationship, we build on the results of Melo-Aguilar et al. (2018) that demonstrate with this ensemble of CESM experiments that external forcings and related (e.g., snow cover) feedbacks can have an impact on SAT-GST coupling, with implications for borehole reconstructions, particularly at regional scales. The work developed herein implements a PPE setup and analysis on the same model ensemble. This allows a consideration of the SAT-GST changes in simulations including a full configuration of natural and anthropogenic forcings and some single-forcing simulations that can aid in the interpretation of the results. Differences between SAT and GST trends and between borehole reconstructions using SAT and GST generated BTPs allow an understanding of the limits of the second hypothesis stated above.

The CESM-LME has been reported to underestimate by $20 \%$ the 20th-century trends (Otto-Bliesner et al., 2016). When considering the ensemble including all natural and anthropogenic forcings (ALL- $F$ ensemble), linear fit GST (SAT) trends vary among ensemble members, ranging between 0.28 and $0.51(0.35$ and 0.60$) \mathrm{K}$ per century. This intersimulation variability is an expected result of changing the initial conditions in order to generate the ensemble and reflects internal variability. We estimate trends during the 20th century as a metric of comparison of simulated and pseudoreconstructed trends by considering the following: (1) differences between the final and initial 15-year periods and (2) linear trends; both approaches are consistent in delivering robust results. Results of the so-called idealized IBS PPE setup, in which sampling in time and space is not limited, produce a similar range of GST trends as the simulations, thus supporting the overall performance of the SVD technique. This method is able to retrieve the long-term trends through the LM and the warming during the industrial period. Thus, the SVD approach itself renders reliable results in terms of retrieving the boundary GST signal. This method shows some sensitivity to an increasing the number of SVD modes. A number of modes consistent with previous modeling and experimental studies were selected here. Results are robust to small changes in this configuration.

A common result that affects all of the subsequent tests in this work is that when methodological and physical constraints are imposed to the borehole reconstruction method, results depend on initial conditions and therefore on internal variability. This is a new although also arguably expected result, as imposing an specific spatial and temporal sampling setup at global and regional scales may produce different effects on 20th-century trends depending on the particular trajectory of internal variability and how effective the distribution of BTPs is in grasping the global and regional warming signals embedded within the range of internal variability. Our findings indicate that sampling can introduce de- 
tectable biases in borehole reconstructions at both global and regional scales. In the specific setup included herein, considering a realistic distribution of depths does not produce any detectable impact. This may be, in part, due to the little signal contained in the synthetic BTPs below 200-300 m depth because the CESM-LME simulations depict relatively low multicentennial surface temperature variability. The distribution of logging dates and BTP locations, on the other hand, does have some impact. At global scales, spatial and temporal masking introduces biases that can range between $>0$ and $0.3 \mathrm{~K}$ per century $\left(\mathrm{GST}-\mathrm{GST}_{\text {mask }}\right.$ and $\mathrm{IBS}_{\mathrm{L} 12}-B_{\text {mask }}$ differences); spatial-only masking reduces maximum differences to $0.1 \mathrm{~K}$ per century. This means that some simulations experience no significant change, and in others masked PPE can experience underestimations of several tenths of a degree depending on the realization of internal variability. These are indeed small numbers, but bear in mind that even a $0.1 \mathrm{~K}$ per century change represents about $20 \%$ of the total warming in these simulations.

At regional scales, the impacts of temporal and spatial sampling vary across regions, with differences (e.g., $\mathrm{IBS}_{\mathrm{L} 12}-B_{\text {mask }}$ ) that can range from 0 to $0.2 \mathrm{~K}$ per century in a relatively well-sampled region such as North America to $0.4 \mathrm{~K}$ per century in Europe or $0.6 \mathrm{~K}$ per century in the African domain. Most of it is due to the temporal sampling effect, particularly in the American and European regions where it gets reduced to values below 0.2 and $0.1 \mathrm{~K}$ per century, respectively, when considering spatial-only masking; in the African domain spatial biases are larger and range between 0.1 and $0.3 \mathrm{~K}$ per century. At regional scales, some of these biases are larger than their target temperature trend values. Thus, at regional scales, spatial and temporal sampling is an issue. The effects are smaller over North America and larger over the other regions tested.

Temporal logging of the borehole records stands as the main sampling aspect contributing to the reduced ability to capture the 20th-century warming. This is because a large portion of the BTPs do not contain information about the warming during the last few decades of the 20th century due to their relatively old logging dates. Such a result suggests that the availability of recent measurements highly influences the results of this type of temperature reconstruction. The continental-scale analysis has provided further insight into this issue since the pseudo-reconstructed GST yields a generally good estimation of the simulated GST evolution during industrial times for areas with a relatively good distribution of recent BTPs measurements, such as the North American continent. On the contrary, this accuracy is lost as the availability of recent BTPs is reduced, as for instance, over the African region. The temporal effects should be relatively small if the reconstructions are considered only up to the dates of the oldest boreholes, at the expense of missing much of the warming developed during the last few decades. Alternatively, strategies may be considered that would blend information from early borehole profiles with local instrumental data to mitigate the missing trend effect (Harris and Chapman, 2001). In addition, this type of analysis would benefit from re-logging of boreholes whenever possible and logging of additional BTPs in the future, thus updating the network. Regarding the spatial sampling effects, the definition of the domains considered herein has been somewhat subjective. Perhaps more ad hoc domain setups that reduce the effects of spatial sampling like in Africa can be specifically considered. Otherwise, cases like the one selected in the African domain, including very sparse sampling, should be avoided.

In the surrogate reality of the CESM-LME, the interpretation of the simulated SAT, derived from the reconstructed GST, is additionally impacted by the physical processes that interrupt the long-term SAT-GST coupling. In the idealized scenario, the GST pseudo-reconstruction does not fully capture the global SAT increase during industrial times, missing about $20 \%$ of the simulated warming on average in the ALL$F$ ensemble. Globally, the larger increase in SAT relative to GST during industrial times arises from the dominant influence of the GHG external forcing. Nevertheless, the contribution of individual forcings varies geographically, as indicated by the regional analysis. While over the North American continent, the overall response is similar to that at the global scale, with a large contribution of the GHG forcing; over Europe and Africa the SAT-GST decoupling is dominated by the LULC forcing.

The impact of the long-term SAT-GST decoupling is superimposed on the limitations due to the methodological aspects. At a global scale, the combined effect results in a biased representation of the simulated SAT 20th-century trend, with the realistic configuration, missing more than $50 \%$ of the simulated SAT (average values for the ensemble). Indeed, at this spatial scale, the largest contribution comes from the methodological aspects. Nonetheless, this may be different at smaller spatial scales. For instance, in North America, where the impact due to the methodological aspects is relatively small, the effect of the SAT-GST decoupling deteriorates the representation of the simulated SAT from the pseudo-reconstructed GST.

Overall, our results indicate that the combined effect of the methodological constraints and the physical SAT-GST decoupling leads to a systematic underestimation of the 20th-century SAT trends at the global scale; at the regional scale overestimations can occur as in the African domain. Nonetheless, it is worth noting that despite this general pattern among the members of the ALL- $F$ ensemble, there may be cases in which these impacts are relatively small or even disappear, consistent with previous studies (González-Rouco et al., 2006; García-García et al., 2016). This influence of internal variability and the comparison with the actual case in the real world can be better evaluated with reanalysis simulations of the 20th century (Hartmann et al., 2013), currently underway.

Even if the analysis included herein represents the most realistic implementation to date of the borehole method in 
PPEs, results are not meant to be directly translated to the real-world cases. Nevertheless, PPEs provide valuable information about the uncertainties in paleo-reconstructions in a controlled experimental framework (Smerdon, 2012). Despite the results of this work indicating a clear pattern in the potential sources of bias that can be found in the boreholebased reconstruction, they should be interpreted with caution for real-world applications since several aspects may influence the level of impact. For instance, the use of other ESMs with different climate sensitivities, i.e., larger 20thcentury warming, and a different representation of the influence of changes in land surface physics could lead to a different representation of changes in the SAT-GST relationship. Additionally, the limitations in the local representation of sampling due to model resolution and more technical issues like the existence of local noise in BTPs have not been considered here. Exploring these issues in future works would be desirable in order to have a more complete evaluation of the method. The latter would be especially interesting if new ensembles of LM simulations with ESMs including both all- and single-forcing experiments were developed in the frame of the CMIP6/PMIP4 (Coupled Model Intercomparison Project phase 6/Paleoclimate Modeling Intercomparison Project phase 4; Eyring et al., 2016, and Jungclaus et al., 2017, respectively). This would allow an exploration of the influence of different external forcing factors and different model physics that have some influence on, for instance, SAT-GST decoupling. To date, this issue can only be addressed with the use of the CESM-LME, as we have done in this study. Additionally, this work clearly supports the need for updating and expanding the borehole network. More and, if possible, deeper and good-quality BTPs are needed.

In light of the results of this work, both the methodological issues and the physical biases of the borehole-based reconstructions would lead to an underestimation of the temperature increase from the LIA to present day, especially over the industrial period. These findings are not able to explain the larger temperature increase suggested by the actual borehole estimations during the last few centuries of the LM relative to those of some other proxy-based reconstructions.

Code and data availability. The code used in this analysis and the results are available from the authors upon request.

Supplement. The supplement related to this article is available online at: https://doi.org/10.5194/cp-16-453-2020-supplement.

Author contributions. This study is part of CMA's PhD. The experimental design was set up by CMA and JFGR. CMA carried out the data processing, analyzed the results and wrote the paper. All of the other authors contributed to the analysis and discussion of the results and to writing the paper.
Competing interests. The authors declare that they have no conflict of interest.

Acknowledgements. We gratefully acknowledge the IlModels (CGL2014-59644-R) and GreatModelS (RTI2018-102305-B-C21) projects. We also thank the CESM1(CAM5) Last Millennium Ensemble Community Project and supercomputing resources provided by the NSF, CISL and Yellowstone.

Financial support. This research has been supported by the Spanish Ministry of Economy, Industry and Competitiveness (grant no. BES-2015-075019).

Review statement. This paper was edited by Jürg Luterbacher and reviewed by two anonymous referees.

\section{References}

Alexeev, V. A., Nicolsky, D. J., Romanovsky, V. E., and Lawrence, D. M.: An evaluation of deep soil configurations in the CLM3 for improved representation of permafrost, Geophys. Res. Lett., 34, 109502, https://doi.org/10.1029/2007GL029536, 2007.

Ammann, C. M. and Wahl, E.: The importance of the geophysical context in statistical evaluations of climate reconstruction procedures, Clim. Change, 85, 71-88, https://doi.org/10.1007/s10584007-9276-x, 2007.

Bartlett, M. G., Chapman, D. S., and Harris, R. N.: Snow effect on North American ground temperatures, 1950-2002, J. Geophys. Res., 110, F03008, https://doi.org/10.1029/2005JF000293, 2005.

Beltrami, H. and Bourlon, E.: Ground warming patterns in the Northern Hmeisphere during the last five centuries, Earth Planet. Sc. Lett., 227, 169-177, 2004.

Beltrami, H. and Mareschal, J. C.: Resolution of ground temperature histories inverted from borehole temperature data, Global Planet. Change, 11, 57-70, 1995.

Beltrami, H., Smerdon, J. E., Matharoo, G. S., and Nickerson, N.: Impact of maximum borehole depths on inverted temperature histories in borehole paleoclimatology, Clim. Past, 7, 745-756, https://doi.org/10.5194/cp-7-745-2011, 2011.

Beltrami, H., Matharoo, G. S., and Smerdon, J. E.: Impact of borehole depths on reconstructed estimates of ground surface temperature histories and energy storage, J. Geophys. Res.-Earth, 120, 763-778, https://doi.org/10.1002/2014JF003382, 2015.

Berger, A., Loutre, M.-F., and Tricot, C.: Insolation and Earth's orbital periods, J. Geophys. Res.-Atmos., 98, 10341-10362, https://doi.org/10.1029/93JD00222, 1993.

Bodri, L. and Cermak, V.: Borehole climatology: a new method how to reconstruct climate, Elsevier Science and Technology, the Netherlands, 3rd edn., 2007.

Carslaw, H. S. and Jaeger, J. C.: Conduction of heat in solids, Oxford Univ. Press, New York, 3rd edn., 1959.

Cermak, V. and Bodri, L.: Attribution of precipitation changes on ground-air temperature offset: Granger causality analysis, Int. J. Earth Sci., 107, 145-152, https://doi.org/10.1007/s00531-0161351-y, 2018. 
Cermak, V., Bodri, L., Kresl, M., Dedecek, P., and Safanda, J.: Eleven years of ground-air temperature tracking over different land cover types, Int. J. Climatol., 37, 1084-1099, https://doi.org/10.1002/joc.4764, 2017.

Chapman, D. S., Bartlett, M. G., and Harris, R. N.: Comment on "Ground vs. surface air temperature trends: implications for borehole surface temperature reconstructions" by M. E. Mann and G. Schmidt, Geophys. Res. Lett., 31, L07205, https://doi.org/10.1029/2003GL019054, 2004.

Eyring, V., Bony, S., Meehl, G. A., Senior, C. A., Stevens, B., Stouffer, R. J., and Taylor, K. E.: Overview of the Coupled Model Intercomparison Project Phase 6 (CMIP6) experimental design and organization, Geosci. Model Dev., 9, 1937-1958, https://doi.org/10.5194/gmd-9-1937-2016, 2016.

Fernández-Donado, L., González-Rouco, J. F., Raible, C. C., Ammann, C. M., Barriopedro, D., García-Bustamante, E., Jungclaus, J. H., Lorenz, S. J., Luterbacher, J., Phipps, S. J., Servonnat, J., Swingedouw, D., Tett, S. F. B., Wagner, S., Yiou, P., and Zorita, E.: Large-scale temperature response to external forcing in simulations and reconstructions of the last millennium, Clim. Past, 9, 393-421, https://doi.org/10.5194/cp-9-393-2013, 2013.

Frank, D., Esper, J., Fraedrich, K., Ziehmann, C., and Sielmann, F.: Adjustment for proxy number and coherence in a large-scale temperature reconstruction, Geophys. Res. Lett., 34, L16709, https://doi.org/10.1029/2007GL030571, 2007.

Gao, C. C., Robock, A., and Ammann, C.: Volcanic forcing of climate over the past 1500 years: an improved ice core-based index for climate models, J. Geophys. Res., 113, D23111, https://doi.org/10.1029/2008JD010239, 2008.

García-García, A., Cuesta-Valero, F. J., Beltrami, H., and Smerdon, J. E.: Simulation of air and ground temperatures in PMIP3/CMIP5 last millennium simulations: implications for climate reconstructions from borehole temperature profiles, Environ. Res. Lett., 11, 044022, https://doi.org/10.1088/17489326/11/4/044022, 2016.

García-García, A., Cuesta-Valero, F. J., Beltrami, H., and Smerdon, J. E.: Characterization of Air and Ground Temperature Relationships within the CMIP5 Historical and Future Climate Simulations, J. Geophys. Res.-Atmos., 124, 3903-3929, https://doi.org/10.1029/2018JD030117, 2019.

González-Rouco, J. F., von Storch, H., and Zorita, E.: Deep soil temperature as proxy for surface air-temperature in a coupled model simulation of the last thousand years, Geophys. Res. Lett., 30, 2116-2119, 2003.

González-Rouco, J. F., Beltrami, H., Zorita, E., and von Storch, H.: Simulation and inversion of borehole temperature profiles in surrogate climates: Spatial distribution and surface coupling, Geophys. Res. Lett., 33, L01703, https://doi.org/10.1029/2005GL024693, 2006.

González-Rouco, J. F., Beltrami, H., Zorita, E., and Stevens, M. B.: Borehole climatology: a discussion based on contributions from climate modeling, Clim. Past, 5, 97-127, https://doi.org/10.5194/cp-5-97-2009, 2009.

Harris, R. N. and Chapman, D. S.: Mid-Latitude (30-60 N) climatic warming inferred by combining borehole temperatures with surface air temperatures, Geophys. Res. Lett., 28, 747-750, 2001.

Hartmann, D., Klein-Tank, A., Rusticucci, M., Alexander, L., Brönnimann, S., Charabi, Y., Dentener, F., Dlugokencky, E., Easterling, D., Kaplan, A., Soden, B., Thorne,
P., Wild, M., and Zhai, P.: Observations: Atmosphere and Surface, book section 2, Cambridge University Press, Cambridge, UK and New York, NY, USA, 159-254, https://doi.org/10.1017/CBO9781107415324.008, 2013.

Houghton, J., Ding, Y., Griggs, D. J., Noguer, M., van der Linden, P. J., Dai, X., Maskell, K., and Johnson, C. A.: Climate Change, 2001: The scientific basis. Contribution of Working Group I to Third Assessment Report of the Intergovernmental Panel on Climate Change, Cambridge University Press, Cambridge, United Kingdom and New York, NY, USA, 2001.

Huang, S. and Pollack, H. N.: Global Borehole Temperature Database for Climate Reconstruction, IGBP PAGES/World Data Center-A for Paleoclimatology Data Contribution Series 1998044, NOAA/NGDC Paleoclimatology Program, Boulder CO, USA. GR1, 1998.

Huang, S., Pollack, H. N., and Shen, P. Y.: Temperature trends over the past five centuries reconstructed from borehole temperatures, Nature, 403, 756-758, 2000.

Hunke, E. C., Lipscomb, W. H., Turner, A. K., Jeffery, N., and Elliott, S.: CICE: the Los Alamos Sea Ice Model Documentation and Software User's Manual Version 5.1, Los Alamos National Laboratory, Los Alamos, NM 87545, 2015.

Hurrell, J. W., Holland, M. M., Gent, P. R., Ghan, S., Kay, J. E., Kushner, P. J., Lamarque, J.-F., Large, W. G., Lawrence, D., Lindsay, K., Lipscomb, W. H., Long, M. C., Mahowald, N., Marsh, D. R., Neale, R. B., Rasch, P., Vavrus, S., Vertenstein, M., Bader, D., Collins, W. D., Hack, J. J., Kiehl, J., and Marshall, S.: The Community Earth System Model: A Framework for Collaborative Research, B. Am. Meteorol. Soc., 94, 13391360, https://doi.org/10.1175/BAMS-D-12-00121.1, 2013.

Hurtt, G. C., Chini, L. P., Frolking, S., Betts, R., Feedema, J., Fischer, G., Goldewijk, K. K., Hibbard, K., Janetos, A., Jones, C., Kindermann, G., Kinoshita, T., Riahi, K., andS. Smith, E. S., Stehfest, E., Thomson, A., Thorton, P., van Vuuren, D., and Wang, Y.: Harmonization of Global Land Use Scenarios for the Period 1500-2100 for IPCC-AR5, Integrated Land EcosystemAtmosphere Processes Study (iLEAPS) Newsletter, 7, 6-8, 2009.

Jansen, E., Overpeck, J., Briffa, K. R., Duplessy, J. C., MassonDelmontte, V., Olago, D., Otto-Bliesner, B., Peltier, W. R., Rahmstorf, S., Ramesh, R., Raynaud, D., Rind, D., Solomina, O., Villalba, R., and Zhang, D.: Paleoclimate, in: Climate Change 2007: The Physical Science Basis. Contribution of Working Group I to the Fourth Assessment Report of the Intergovernmental Panel on Climate Change, edited by: Solomon, S., Qin, D., Manning, M., Chen, Z., Marquis, M., Averyt, K. B., Tignor, M., and Miller, H. L., Cambridge University Press, Cambridge, UK and New York, NY, USA, 2007.

Jaume-Santero, F., Pickler, C., Beltrami, H., and Mareschal, J.-C.: North American regional climate reconstruction from ground surface temperature histories, Clim. Past, 12, 2181-2194, https://doi.org/10.5194/cp-12-2181-2016, 2016.

Jones, P. D., Briffa, K. R., Osborn, T. J., Lough, J. M., Van Ommen, T. D., Vinther, B. M., Luterbacher, J., Wahl, E. R., Zwiers, F. W., Mann, M. E., Schmidt, G. A., Ammann, C. M., Buckley, B. M., Cobb, K. M., Esper, J., Goose, H., Graham, N., Jansen, E., Kiefer, T., Kull, C., Küttel, M., Mosley-Thompson, E., Overpeck, J. T., Riedwyl, N., Schulz, M., Tudhope, A. W., Villalba, R., Wanner, H., Wilff, E., and Xoplake, E.: Highresolution palaeoclimatology of the last millennium: A review 
of current status and future prospects, Holocene, 19, 3-49, https://doi.org/10.1177/0959683608098952, 2009.

Jungclaus, J. H., Bard, E., Baroni, M., Braconnot, P., Cao, J., Chini, L. P., Egorova, T., Evans, M., González-Rouco, J. F., Goosse, H., Hurtt, G. C., Joos, F., Kaplan, J. O., Khodri, M., Klein Goldewijk, K., Krivova, N., LeGrande, A. N., Lorenz, S. J., Luterbacher, J., Man, W., Maycock, A. C., Meinshausen, M., Moberg, A., Muscheler, R., Nehrbass-Ahles, C., Otto-Bliesner, B. I., Phipps, S. J., Pongratz, J., Rozanov, E., Schmidt, G. A., Schmidt, H., Schmutz, W., Schurer, A., Shapiro, A. I., Sigl, M., Smerdon, J. E., Solanki, S. K., Timmreck, C., Toohey, M., Usoskin, I. G., Wagner, S., Wu, C.-J., Yeo, K. L., Zanchettin, D., Zhang, Q., and Zorita, E.: The PMIP4 contribution to CMIP6 - Part 3: The last millennium, scientific objective, and experimental design for the PMIP4 past 1000 simulations, Geosci. Model Dev., 10, 40054033, https://doi.org/10.5194/gmd-10-4005-2017, 2017.

Lawrence, D. M., Oleson, K. W., Flanner, M. G., Thornton, P. E., Swenson, S. C., Lawrence, P. J., Zeng, X., Yang, Z.-L., Levis, S., Sakaguchi, K., Bonan, G. B., and Slater, A. G.: Parameterization improvements and functional and structural advances in Version 4 of the Community Land Model, J. Adv. Model. Earth Syst., 3, m03001, https://doi.org/10.1029/2011MS00045, 2011.

Legutke, S. and Voss, R.: The Hamburg Atmosphere-Ocean Coupled Circulation Model ECHO-G, Tech. Rep. 18, DKRZ, Hamburg, 1999.

MacDougall, A. H. and Beltrami, H.: Impact of deforestation on subsurface temperature profiles: implications for the borehole paleoclimate record, Environ. Res. Lett., 12, 074014, https://doi.org/10.1088/1748-9326/aa7394, 2017.

MacDougall, A. H., González-Rouco, J. F., Stevens, M. B., and Beltrami, H.: Quantification of subsurface heat storage in a GCM simulation, Geophys. Res. Lett., 35, L13702, https://doi.org/10.1029/2008GL034639, 2008.

MacFarling Meure, C., Etheridge, D., Trudinger, C., Steele, P., Langenfelds, R., Van Ommen, T., Smith, A., and Elkins, J.: Law Dome $\mathrm{CO}_{2}, \mathrm{CH}_{4}$ and $\mathrm{N}_{2} \mathrm{O}$ ice core records extended to 2000 years BP, Geophys. Res. Lett., 33, L14810, https://doi.org/10.1029/2006GL026152, 2006.

Mann, M. E. and Schmidt, G. A.: Ground vs. Surface air temperature trends: implications for borehole surface temperature reconstructions, Geophys. Res. Lett., 30, 1607, https://doi.org/10.1029/2003GL017170, 2003.

Mareschal, J.-C. and Beltrami, H.: Evidence for recent warming from perturbed geothermal gradients: examples from eastern Canada, Clim. Dynam., 6, 135-143, https://doi.org/10.1007/BF00193525, 1992.

Masson-Delmotte, V., Schulz, M., Abe-Ouchi, A., Beer, J., Ganopolski, A., González Rouco, J., Jansen, E., Lambeck, K., Luterbacher, J., Naish, T., Osborn, T., Otto-Bliesner, B., Quinn, T., Ramesh, R., Rojas, M., Shao, X., and Timmermann, A.: Information from Paleoclimate Archives, book section 5, Cambridge University Press, Cambridge, UK and New York, NY, USA, 383464, https://doi.org/10.1017/CBO9781107415324.013, 2013.

Melo-Aguilar, C., González-Rouco, J. F., García-Bustamante, E., Navarro-Montesinos, J., and Steinert, N.: Influence of radiative forcing factors on ground-air temperature coupling during the last millennium: implications for borehole climatology, Clim. Past, 14, 1583-1606, https://doi.org/10.5194/cp-14-1583-2018, 2018.
Neale, R. B., Gettelman, A., Park, S., Conley, A. J., Kinnison, D., Marsh, D., Smith, A. K., Vitt, F., Morrison, H., Cameron-smith, P., Collins, W. D., Iacono, M. J., Easter, R. C., Liu, X., Taylor, M. A., Chieh Chen, C., Lauritzen, P. H., Williamson, D. L., Garcia, R., Lamarque, F. J., Mills, M., Tilmes, S., Ghan, S. J., and Rasch, P. J.: Description of the NCAR Community Atmosphere Model (CAM 5.0), Tech. Note NCAR/TN-486+STR, Natl. Cent. for Atmos, pp. 1-289, available at: http://www.cesm.ucar.edu/ models/cesm1.0/cam/docs/description/cam5_desc.pdf (last access: 2 March 2020), 2012.

Oleson, K. W., Lawrence, D. M., B, G., Flanner, M. G., Kluzek, E., J, P., Levis, S., Swenson, S. C., Thornton, E., Feddema, J., Heald, C. L., francois Lamarque, J., yue Niu, G., Qian, T., Running, S., Sakaguchi, K., Yang, L., Zeng, X., Zeng, X., and Decker, M.: Technical Description of version 4.0 of the Community Land Model (CLM), Tech. Note NCAR/TN-478+STR, Natl. Cent. for Atmos, https://doi.org/10.5065/D6FB50WZ, 2010.

Otto-Bliesner, B. L., Brady, E. C., Fasullo, J., Jahn, A., Landrum, L., Stevenson, S., Rosenbloom, N., Mai, A., and Strand, G.: Climate Variability and Change since $850 \mathrm{CE}$ : An Ensemble Approach with the Community Earth System Model, B. Am. Meteorol. Soc., 97, 735-754, https://doi.org/10.1175/BAMS-D-14$00233.1,2016$.

Pollack, H. N. and Huang, S.: Climate reconstruction from subsurface temperatures, Annu. Rev. Earth. Planet. Sci., 28, 339-365, 2000.

Pollack, H. N. and Smerdon, J. E.: Borehole climate reconstructions: spatial structure and hemispheric averages, J. Geophys. Res., 109, D11106, https://doi.org/10.1029/2003JD004163, 2004.

Pongratz, J., Reick, C., Raddatz, T., and Claussen, M.: A reconstruction of global agricultural areas and land cover for the last millennium, Global Biogeochem. Cycles, 22, gB3018, https://doi.org/10.1029/2007GB003153, 2008.

Rutherford, S. and Mann, M. E.: Correction to "Optimal surface temperature reconstructions using terrestrial borehole data", J. Geophys. Res., 109, D11107, https://doi.org/10.1029/2003JD004290, 2004.

Santer, B. D., Thorne, P. W., Haimberger, L., Taylor, K. E., Wigley, T. M. L., Lanzante, J. R., Solomon, S., Free, M., Gleckler, P. J., Jones, P. D., Karl, T. R., Klein, S. A., Mears, C., Nychka, D., Schmidt, G. A., Sherwood, S. C., and Wentz, F. J.: Consistency of modelled and observed temperature trends in the tropical troposphere, Int. J. Climatol., 28, 1703-1722, https://doi.org/10.1002/joc.1756, 2008.

Schmidt, G. A. and Mann, M. E.: Reply to Comment on "Ground vs. surface air temperature trends: implications for borehole surface temperature reconstructions" by M. E Mann and G. Schmidt, Geophys. Res. Lett., 31, L07206, https://doi.org/10.1029/2003GL019144, 2004.

Schmidt, G. A., Jungclaus, J. H., Ammann, C. M., Bard, E., Braconnot, P., Crowley, T. J., Delaygue, G., Joos, F., Krivova, N A., Muscheler, R., Otto-Bliesner, B. L., Pongratz, J., Shindell, D. T., Solanki, S. K., Steinhilber, F., and Vieira, L. E. A.: Climate forcing reconstructions for use in PMIP simulations of the last millennium (v1.0), Geosci. Model Dev., 4, 33-45, https://doi.org/10.5194/gmd-4-33-2011, 2011.

Schmidt, G. A., Jungclaus, J. H., Ammann, C. M., Bard, E., Braconnot, P., Crowley, T. J., Delaygue, G., Joos, F., Krivova, N. 
A., Muscheler, R., Otto-Bliesner, B. L., Pongratz, J., Shindell, D. T., Solanki, S. K., Steinhilber, F., and Vieira, L. E. A.: Climate forcing reconstructions for use in PMIP simulations of the Last Millennium (v1.1), Geosci. Model Dev., 5, 185-191, https://doi.org/10.5194/gmd-5-185-2012, 2012.

Smerdon, J. E.: Climate models as a test bed for climate reconstruction methods: pseudoproxy experiments, WIREs Clim. Change, 3, 63-77, https://doi.org/10.1002/wcc.149, 2012.

Smerdon, J. E., Pollack, H. N., Cermak, V., Enz, J. W., Kresl, M., Safanda, J., and Wehmiller, J. F.: Air-ground temperature coupling and subsurface propagation of annual temperature signals, J. Geophys. Res., 109, D21107, https://doi.org/10.1029/2004JD005056, 2004.

Smith, R., Jones, P., Briegleb, B., Bryan, F., Danabasoglu, G., Dennis, J., Dukowicz, J., Eden, C., Fox-Kemper, B., Gent, P., Hecht, M., Jayne, S., M. Jochum, W. Large, K. L., Maltrud, M., Norton, N., Peacock, S., Vertenstein, M., and Yeager, S.: The Parallel Ocean Program (POP) Reference Manual, Tech. Rep. LAUR10-01853, Los Alamos National Laboratory, available at: http: //tinyurl.com/SJBBD10/doc/sci/POPRefManual.pdf (last access: 2 March 2020), 2010.
Stevens, M. B., Smerdon, J. E., González-Rouco, J. F., Stieglitz, M., and Beltrami, H.: Effects of bottom boundary condition placement on subsurface heat storage: Implications for climate model simulations, Geophys. Res. Lett., 34, L02702, https://doi.org/10.1029/2006GL028546, 2007.

Storch, H. V. and Zwiers, F. W.: Statistical Analysis in Climate Research, Cambridge University Press, Cambridge, https://doi.org/10.1017/CBO9780511612336, 1999.

Taylor, K. E., Stouffer, R. J., and Meehl, G. A.: An Overview of CMIP5 and the Experiment Design, B. Am. Meteorol. Soc., 93, 485-498, https://doi.org/10.1175/BAMS-D-11-00094.1, 2012.

Vieira, A., Solanki, S. K., Krivova, N. A., and Usoskin, I.: Evolution of the solar irradiance during the Holocene, Astronomy \& Astrophysics, 531, 1-20, https://doi.org/10.1051/00046361/201015843, 2011. 